Analysis of Tracer Responses in the BULLION Forced-Gradient

Experiment at Pahute Mesa, Nevada

Paul W. Reimus

Marc J. Haga 



\section{DISCLAIMER}

This report was prepared as an account of work sponsored by an agency of the United States Government. Neither the United States Government nor any agency thereof, nor any of their employees, make any warranty, express or implied, or assumes any legal liability or responsibility for the accuracy, completeness, or usefulness of any information, apparatus, product, or process disclosed, or represents that its use would not infringe privately owned rights. Reference herein to any specific commercial product, process, or service by trade name, trademark, manufacturer, or otherwise does not necessarily constitute or imply its endorsement, recommendation, or favoring by the United States Government or any agency thereof. The views and opinions of authors expressed herein do not necessarily state or reflect those of the United States Government or any agency thereof. 


\section{DISCLAIMER}

Portions of this document may be illegible in electronic image products. Images are produced from the best available original document. 


\section{Table of Contents}

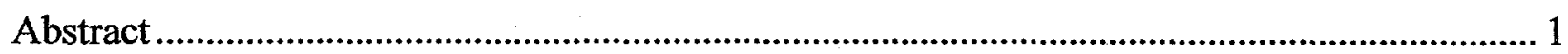

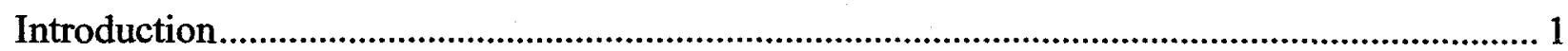

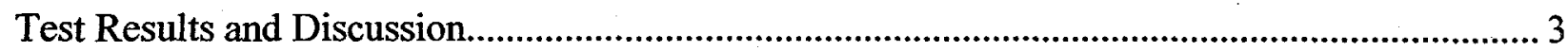

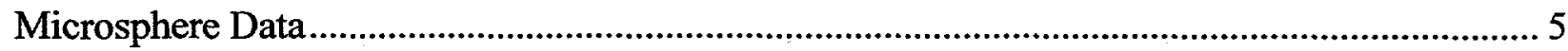

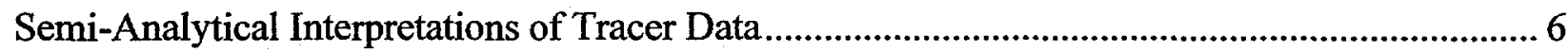

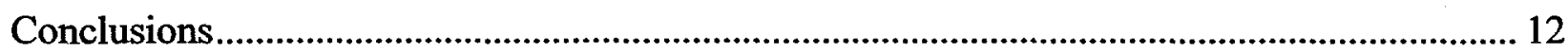

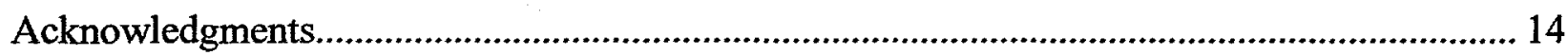

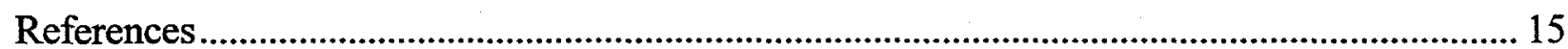

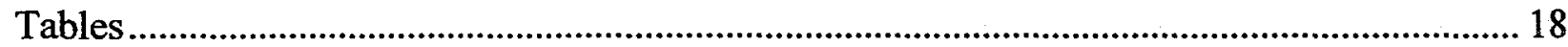

Figures.

Appendix A .

Appendix B

\section{List of Tables}

Table 1. Injection masses/numbers of tracers in each injection well........................................18

Table 2. Fractional recoveries of tracers in each well............................................................18

Table 3. Transport parameters deduced from fits to cross-hole tracer responses. ........................19

Table 4. Well 1-3 and Well 1-2 solute transport parameter estimates as a function of assumed diffusion coefficient ratios and injection wellbore residence times (linear flow)....................20

\section{List of Figures}

Figure 1. Schematic showing layout of wells used for the BULLION forced-gradient experiment (taken from IT, 1998).

Figure 2. Hydrogeologic cross-section through the wells used for the BULLION FGE (taken from IT, 1998).

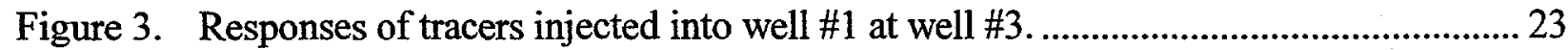

Figure 4. Responses of tracers injected into well \#2 at well \#3..................................................23

Figure 5. Responses of tracers injected into well \#1 at well \#2 ................................................. 24

Figure 6. Pumpback responses of tracers injected into well \#1 ................................................. 24

Figure 7. Pumpback responses of tracers injected into well \#2 .................................................25

Figure 8. Tracer concentrations (normalized to injection concentrations) in discrete bailer samples from well \#1. ............................................................................................................. 25 
Figure 9. Tracer concentrations (normalized to injection concentration) in discrete bailer samples from well \#2.

Figure 10. Microsphere responses as a function of time since injection into well \#2................. 26

Figure 11. Flow rate (upper curve) and pressure drawdown (lower curve) history in well \#3 (taken from IT, 1998).

Figure 12. Physical system, conceptual model, and Laplace transform transfer functions used to interpret tracer tests. 28

Figure 13. RELAP model fits to tracer responses between well \#1 and well \#3. 29

Figure 14. RELAP model fits to tracer responses between well \#2 and well \#3. 30

Figure 15. RELAP model fits to tracer responses between well \#1 and well \#2. 31

Figure 16. Plot of longitudinal dispersivity vs. length scale showing range of values derived from interpretations of the BULLION FGE tracer responses (blackened area). 32 


\title{
Analysis of Tracer Responses in the BULLION \\ Forced-Gradient Experiment at Pahute Mesa, Nevada
}

\author{
Paul W. Reimus \\ Marc J. Haga
}

\begin{abstract}
This report presents an analysis of the tracer data from the BULLION forced-gradient experiment (FGE) conducted on Pahute Mesa at the Nevada Test Site from June 2, 1997 through August 28, 1997, for the Underground Test Area (UGTA) Program. It also serves to document the polystyrene microsphere data from the FGE. The FGE involved the injection of solute and colloid tracers into wells ER-20-6 \#1 and ER-20-6 \#2 while ER-20-6 \#3 was pumped at approximately 116 gallons per minute (gpm). The experimental configuration and test design are described briefly in this report; more details are provided elsewhere (IT, 1996, 1997, 1998). The tracer responses in the various wells yielded valuable information about transport processes such as longitudinal dispersion, matrix diffusion and colloid transport in the hydrogeologic system in the vicinity of the BULLION nuclear test cavity. Parameter values describing these processes are derived from the semi-analytical model interpretations presented in this report. A companion report (IT, 1998) presents more detailed numerical modeling interpretations of the solute tracer responses.
\end{abstract}

\section{Introduction}

The Underground Test Area (UGTA) Program at the Nevada Test Site (NTS) is pursuing characterization of potential groundwater contamination from underground nuclear tests. Radionuclides released to the groundwater system by these tests may migrate offsite and could potentially affect groundwater supplies downgradient of the test areas. Available evidence suggests that water flow in the hydrogeologic units below the water table occurs predominantly in fractures (Drellack and Prothro, 1997; Blankennagel and Weir, 1973). However, most of the water volume in the system is contained in the pores of the tuff and lava flow matrices that comprise the bulk geology. In most units, this matrix water is expected to be essentially stagnant compared to the water moving through fractures. Radionuclide transport is therefore expected to be attenuated by diffusive mass transfer between the flowing water in the fractures and the stagnant water in the matrix, a process known as matrix diffusion. Matrix diffusion in fractured systems has been discussed and modeled at length by others (Neretnieks, 1980; Grisak and Pickens, 1980; Tang et al., 1981; Maloszewski and Zuber, 1983, 1985). A system exhibiting this type of behavior is frequently called a "dual-porosity" system because of the two distinct porosities corresponding to the fractures and the matrix. We distinguish such a system from a "dual-permeability" or a "dual-porosity, dual-permeability" system because it is assumed that the 
matrix permeability is negligible relative to fracture permeability and that essentially all flow occurs in fractures. This assumption may not hold in all hydrogeologic units at the NTS, but it is expected to be valid in the most transmissive ones that are likely to transport radionuclides the greatest distances. The objectives of the BULLION FGE included (1) testing this conceptual model and (2) obtaining estimates of transport parameters describing dispersion, matrix diffusion, and colloid transport at the field scale.

The experimental design of the BULLION FGE, including the site hydrogeology, well completion and configuration, and surface plumbing, is described in detail elsewhere (IT, 1996, 1997, 1998). Figure 1 shows a schematic layout of the three wells used in the FGE. These wells are located approximately in a line heading in a south-southwesterly direction away from the BULLION test cavity. A schematic summarizing the hydrogeology and well completions at the site is provided in Figure 2. The wells are completed over approximately a 120-m interval of mostly devitrified lava within the Calico Hills formation at a depth ranging from approximately 145 to $265 \mathrm{~m}$ below the water table. The natural gradient at the site is estimated to be from northeast to southwest (IT, 1997), or approximately in the direction from well \#1 to well \#3.

Pumping of well ER-20-6 \#3 at 116 gpm was initiated on June 2, 1997. Pentafluorobenzoic acid (PFBA) and 0.33- $\mu \mathrm{m}$ diameter carboxylate-modified latex (CML) polystyrene microspheres (Interfacial Dynamics, Inc.) were simultaneously injected into ER-20-6 \#2 on June 3,1997. By simultaneous injection, we mean that the tracers were mixed in the same solution and injected together. On June 6, iodide (as sodium iodide), 2,6 difluorobenzoic acid (DFBA), and 0.33- $\mu \mathrm{m}$ diameter CML microspheres were simultaneously injected into ER-20-6 \#1. The microspheres injected into the two wells were identical except that they were tagged with different fluorescent dyes (yellow in well \#2 and red in well \#1) to allow them to be distinguished from one another. Injection masses (or numbers in the case of the microspheres) are listed in Table 1. Volumes of the injectate solutions were approximately 6,000 gallons in each injection well. The solutes were analyzed by high-pressure liquid chromatography with a UV absorbance detector, and the microspheres were analyzed by flow cytometry (Steinkamp et al. 1991, Becker et al., 1999). All of the solute tracers were expected to be conservative (nonsorbing) under the geochemical conditions at the site (most notably a pH greater than 7).

Pumping of both injection wells at $\sim 5 \mathrm{gpm}$ was initiated within 3 days of tracer injection (well \#2 on June 6, and well \#1 on June 8). This pumping was conducted in part to sample for radionuclides in water that was being drawn from the direction of the BULLION cavity by the $116 \mathrm{gpm}$ pumping of well \#3, but it also provided a tracer pumpback test of sorts from both injection wells, and it allowed quantification of tracer transport between wells \#1 and \#2.

The polystyrene microspheres were used for two purposes: (1) they served as colloid tracers to provide insights into the potential for colloidal radionuclide transport in the saturated zone on Pahute Mesa, and (2) they served as large, low diffusivity tracers that should be excluded from the matrix and hence provide an indication of true fracture flow in the system without the effects of matrix diffusion. CML microspheres were used because these microspheres had previously been shown to have less tendency for attenuation/filtration in fractured systems than other synthetic colloids that we have considered (Reimus, 1995). The spheres have a density of $1.055 \mathrm{~g} / \mathrm{cm}^{3}$, which minimizes their tendency to settle in groundwater. The fluorescent dye tags allowed the spheres to be discriminated from natural colloidal material and to be quantified at concentrations as low as $\sim 100 / \mathrm{ml}$ using flow cytometry (Steinkamp et al., 1991; Becker et al., 1999). The CML spheres have carboxyl functional groups on their surfaces, 
which give them a negative surface charge at $\mathrm{pHs}$ greater than about 5; and unlike most other polystyrene microspheres, they also have hydrophilic surfaces (Wan and Wilson, 1994). Both of these features tend to minimize attractive interactions with rock surfaces, and they make the spheres very stable against flocculation, even at relatively high ionic strengths, which is important if the spheres are to be injected simultaneously with solutes in a relatively concentrated solution. We used $0.33-\mu \mathrm{m}$-diameter spheres because we found in previous work that larger spheres were more attenuated in fractured systems, possibly due to more rapid settling of the larger particles (Becker et al., 1999). Also, the flow cytometer that we had access to had a lower size detection limit of about $0.25-\mu \mathrm{m}$ diameter, although this does not represent a fundamental limitation of the technique.

By simultaneously introducing the tracers into each injection well, it could be assumed that they all experienced the same flow field and hence followed identical flow pathways through the system. This allowed the test interpretations to be based on comparing the responses of the different tracers in addition to analyzing individual tracer responses. A comparison of the responses of conservative tracers with different diffusion coefficients can yield valuable insights into matrix diffusion processes, as more diffusive tracers are expected to diffuse more readily into the matrix and hence have lower peak concentrations and longer breakthrough curve tails than less diffusive tracers. Quantitative analyses of these differences allow the effects of flowfield dispersion and matrix diffusion to be separated and ultimately yield better estimates of parameters describing both processes.

This report presents the tracer data from the FGE and semi-analytical interpretations of the cross-hole solute and microsphere responses. A companion report (IT, 1998) presents the hydraulic responses in each well during the FGE, their interpretations, and more detailed numerical modeling interpretations of the solute tracer responses.

\section{Test Results and Discussion}

Breakthrough curves of tracers in each well are shown in Figures 3 through 7 . Figures 3 and 4 show the responses in well \#3 of the tracers injected into wells \#1 and \#2, respectively. Figure 5 shows the responses in well \#2 of the tracers injected into well \#1. Figures 6 and 7 show the pumpback responses of tracers in wells \#1 and \#2, respectively (note log concentration scale). All breakthrough curves are normalized to the mass (or number, in the case of the microspheres) injected, with units of $1 / \mathrm{L} \mathrm{X} 10^{9}$ (equivalent to $\mu \mathrm{g} / \mathrm{L}$ per $\mathrm{kg}$ injected) The gaps in the data from wells $\# 1$ and $\# 2$ correspond to periods when the pumps were turned off. In addition to sampling the pumped water from the injection wells, we obtained discrete bailer samples from both the upper and lower portions of the injection zones. These results are plotted in Figures 8 and 9 for wells \#1 and \#2, respectively. The results indicate that there was not a significant difference between the upper and lower zone concentrations of any of the tracers, although there were clearly a few outliers in the data. The early microsphere data from the bailed samples in well \#2 are not of particularly good quality because of the high concentrations measured and the fact that the flow cytometer used for the analyses was unavailable for repeat measurements using diluted samples. The analyses of the bailed samples were given a lower priority than the pumped samples because they were not considered as important for test interpretation. 
Examination of the cross-hole tracer breakthrough curves in Figures 3 and 5 qualitatively suggests that matrix diffusion occurred in the flow system. The higher peak concentration of the 2,6-DFBA relative to the iodide in both cases and the hint of a crossover of the tails of the breakthrough curves are both consistent with matrix diffusion. This behavior is more apparent in Figure 3 than Figure 5 because of the greater travel time involved for the tracers to move from well \#1 to well \#3 than from well \#1 to well \#2 and the correspondingly greater time for matrix diffusion to occur. The iodide response is expected to have a lower peak concentration and a longer tail than 2,6-DFBA because iodide is a smaller anion, and it therefore should diffuse more readily into the matrix than the DFBA. Laboratory experiments have shown that iodide has a factor of 2.5 to 3 larger diffusion coefficient than PFBA (Reimus et al., 1999a). PFBA and 2,6DFBA should have nearly identical diffusion coefficients (Benson and Bowman, 1994).

The cross-hole tracer responses between wells \#2 and \#3 (Figure 4) do not offer a clearcut assessment of matrix diffusion because (1) there is only one solute tracer, which precludes a comparison between solutes of different diffusion coefficients, and (2) the microspheres were clearly attenuated by filtration, which makes it impossible to assume that they behaved as ideal conservative tracers with a very low diffusion coefficient.

An interesting aspect of the microsphere responses in well \#3 is the second peak that occurred for both the red and the yellow microspheres. In contrast to the first peaks of these spheres, the second peaks were coincident in time and were not associated with any peaks or noticeable inflections in the solute responses. Figure 10 shows the microsphere responses plotted as a function of time since injection into well \#2 (the earliest injection). The most probable explanation for this behavior is a flow interruption at well \#3 due to a pump shutdown that occurred at just about the time the second peak began. During this interruption, backflow into the formation occurred as a result of a failed check valve in the discharge line. When the pump was restarted, the pressure drawdown in well \#3 did not revert to its pre-interruption value, suggesting that the characteristics of the formation were irreversibly altered during the flow interruption, with less near-wellbore flow resistance after the interruption. A pumping rate and pressure drawdown history for well \#3 is plotted in Figure 11. The backflow and possible opening of fractures could have dislodged microspheres that were attached to rock surfaces in the vicinity of the wellbore, thus resulting in the second peak. This is not the only plausible explanation for the second peak, but it is consistent with the coincident timing of the peaks for the two microspheres.

The pumpback responses from well \#1 (Figure 6) suggest that matrix diffusion in the vicinity of this well was minimal because the responses of the iodide and 2,6-DFBA are nearly identical. If matrix diffusion were significant, the recovery of the DFBA would be greater than iodide at early times and there would be a crossover at later times. Also, the microsphere response is quite similar to the solute responses, which argues against matrix diffusion. However, the slight increase in tracer concentrations after extended pump shutdown is consistent with matrix diffusion, as the tracer concentrations would be expected to increase as a result of tracer mass diffusing out of the matrix and into fractures during the flow interruption.

The pumpback responses from well \#2 (Figure 7) suggest the possibility of more matrix diffusion in the vicinity of this well than well \#1. This supposition is based on the microsphere recovery being greater than that for the PFBA. However, without a second solute tracer to compare to the PFBA, this hypothesis should be considered very tentative. It is also curious and counter to matrix diffusion arguments that the PFBA concentrations in well $\# 2$ decreased rather 
than increased after the pump shutdowns. In a dual-porosity system, an increase in solute concentrations is expected after a flow interruption in the tail of a breakthrough curve because the cessation of flow allows time for solutes to diffuse out of the matrix and into the fractures.

The fractional recoveries of tracers in each well are listed in Table 2. It is interesting and somewhat puzzling that the recoveries are as low as they are, especially considering that the injection wells were pumped back to ensure recovery of tracers lingering near these wells. This behavior suggests considerable losses to the formation, presumably due to either matrix diffusion or movement of tracers out of the zone of influence of pumping. The latter could be explained either by the effects of the natural gradient in a highly heterogeneous system or by density effects (i.e., the more dense tracer solution could have sunk into the formation below the bottom of the injection boreholes). However, the tracer solutions were less than $1 \%$ more dense than the groundwater, and over ten screened-interval volumes of solution were injected, so it seems unlikely that density effects could have accounted for all of the unrecovered mass. Another possibility is that the combined pumping of all three wells at various times resulted in stagnation points that significantly retarded the movement of tracers through the system. An additional possibility is that there could have been a significant amount of low velocity but high volumetric flow through the matrix. This high volumetric flow could have carried most of the tracer mass away from the injection wells, but it was too slow to move the tracers to the production wells during the $\sim 3$ months of testing. However, this possibility is not supported by the low pumpback recoveries from the injection wells; if there were significant low-velocity flow in the matrix, it seems likely that tracers moving through this flow would have been recovered when the wells were pumped back. These are all unproven conjectures, and the possibility of other explanations certainly exists. The possibility of matrix diffusion as an explanation for the low recoveries will be addressed in the interpretations section of this report.

\section{Microsphere Data}

Spreadsheet tabulations of the microsphere data from the BULLION FGE are provided in Appendix A. This appendix constitutes the final microsphere data package for the FGE. The microsphere analyses were conducted in accordance with approved standard operating procedure LANL-CST-04, Rev. 0, entitled "Use of a Flow Cytometer to Determine Particle Concentrations in Solution" (Reimus, 1997). Measurements that were rejected as outliers are noted with an asterisk in the tables. Repeat measurements on solutions that contained about 8,000 spheres $/ \mathrm{ml}$ indicated a measurement precision of $~ 5 \%$ ( $95 \%$ confidence interval). However, the measurement precision was almost certainly lower than this in most of the groundwater samples from the FGE, which had microsphere concentrations less than $1,000 / \mathrm{ml}$ in general. The total number of red and yellow spheres injected into wells $\# 1$ and $\# 2$, respectively, was determined by averaging many repeat measurements on dilutions of small portions of the total sphere inventory suspended in 2 liters of water. The results of these measurements are not included in Appendix $\mathrm{A}$, but they are available on request. 


\section{Semi-Analytical Interpretations of Tracer Data}

\section{Scope}

The solute and microsphere data were analyzed to obtain estimates of transport parameters using a relatively simple semi-analytical model that assumes a homogeneous dualporosity system and steady flow between the tracer injection and production locations. This model and its application are described in detail in the next section and also in Appendix B. The analyses were limited to the cross-hole tests for two reasons: (1) the pumpback tests showed no clear evidence of matrix diffusion based on differences in solute responses (the solute responses in well \#1 were nearly identical), and (2) the interpretation of the pumpback responses is greatly complicated by the fact that there was a two- to three-day shut-in period, and during this time there was an induced gradient to move tracers through the groundwater system. Classical analysis of injection-withdrawal tests to estimate matrix diffusion parameters assumes ideal mixing in the injection wellbore and negligible advection in the formation during the shut-in period so that all tailing of the tracer response(s) can be attributed to matrix diffusion (Meigs et al., 1996). Also, injection-withdrawal tests typically have very high recoveries (greater than $90 \%$ ), which are often used as a measure of test quality. These situations were clearly not the case in the BULLION FGE, and it has been shown (Lessoff and Konikow, 1997) that tracer movement under natural or forced-gradient conditions with an extended shut-in period can result in significant tailing that looks very much like matrix diffusion even when matrix diffusion is not occurring. The pumpback responses of multiple tracers with different diffusion coefficients are still expected to yield information on matrix diffusion, but, as noted above, there were no apparent differences in the responses of iodide and 2,6-DFBA in well \#1. Analyses of these responses would therefore be expected to yield no information on matrix diffusion, and pumpback test data typically does not yield any information on dispersion or effective flow porosity in the formation. Thus, analysis of the pumpback responses is reserved for more detailed numerical modeling that can account for flow field effects and other subtleties that may have affected the responses in a way that cannot be captured in relatively simple semi-analytical modeling.

\section{Description of Semi-Analytical Model}

The solute tracer responses were interpreted by simultaneously fitting the cross-hole breakthrough curves using a semi-analytical, dual-porosity transport model, REactive transport LAPlace transform inversion code (RELAP), which is described in detail in Appendix B and briefly summarized here. The physical, conceptual, and mathematical models assumed for the field transport system are depicted in Figure 12. The equations shown at the bottom of Figure 12 are Laplace-domain "transfer functions" that describe tracer residence time distributions within each of the system "components." The most important of these is the transfer function for the groundwater system, which is taken from Tang et al., 1981. This transfer function assumes 1dimensional advective-dispersive transport in parallel-plate fractures with 1-dimensional diffusion (perpendicular to fracture flow) into a homogeneous, infinite matrix. It also assumes linear, reversible equilibrium sorption of reactive solutes and a constant flow velocity in the fractures. Model formulations assuming a finite matrix (Maloszewski and Zuber, 1983, 1985), 
radial flow (Moench, 1995; Becker, 1996) and rate-limited sorption (Maloszewski and Zuber, 1991) are also embodied in RELAP. These were used to evaluate the sensitivity of the derived transport parameters to radial vs. linear flow, infinite vs. finite matrix, and equilibrium vs. ratelimited sorption. The reactive transport features of RELAP were used only to model microsphere filtration, as all the conservative solutes were assumed to have retardation coefficients of unity in both the fractures and the matrix. A detailed description of the mathematical development of the models embodied in RELAP is provided in Appendix B. Much of this appendix focuses on the reactive transport features of RELAP, which were not used in any detail here (other than for the microspheres), but their discussion is included for completeness.

The transfer functions shown in Figure 12 were multiplied together to describe transport throughout the system; a multiplication in the Laplace domain is equivalent to a convolution integral in the time domain (Churchill, 1958). Wellbore storage was accounted for by assuming that the boreholes were well-mixed, with the tracers experiencing an exponential-decay residence time distribution with a time constant approximately equal to the volume of the interval divided by the volumetric flow rate into (injection well) or out of (production well) the interval. Note that a transfer function is not shown in Figure 12 for the production well because residence times in production wells are typically short enough that this transfer function can be ignored. The Laplace domain solutions were then inverted to the time domain using a Fourier-transform inversion technique (Appendix B). Because the Fourier-transform technique is very efficient (and stable), it could be performed thousands of times per minute on a computer workstation, making it practical to estimate model parameters by systematic, brute-force adjustments of their values to achieve a least-squares fit to multiple data sets. The fitting procedure used to quantitatively interpret the tracer responses is discussed in detail in the following section.

\section{Interpretation Procedure}

The first step in the interpretation procedure involved using the transfer function model depicted in Figure 12 to simultaneously fit the 2,6-DFBA and iodide data in wells \#2 and \#3 assuming that all transport parameters except for diffusion coefficients were identical for the two solutes. The iodide matrix diffusion coefficient was assumed to be 2.7 times that of 2,6-DFBA based on the average iodide-to-PFBA diffusion coefficient ratio determined in laboratory diffusion cell experiments (Reimus et al., 1999a). The matrix and fracture retardation factors for these two nonsorbing tracers were fixed at 1 . The procedure involved simultaneously fitting the tracer responses by systematically adjusting several parameters in the model. The parameters adjusted to achieve a fit were (1) the mass fraction, $\mathrm{f},(2)$ the mean fluid residence time, $\tau,(3)$ the Peclet number, $\mathrm{Pe}=\mathrm{L} / \alpha$, where $\mathrm{L}$ is the distance between wells and $\alpha$ is the longitudinal dispersivity, and (4) $\frac{\phi}{b} \sqrt{D_{m}}$, an effective mass transfer coefficient for diffusion into stagnant water, assumed to be in the matrix. These parameters were constrained to have the same values for each tracer for a given injection-production well pair except that the ratio of iodide diffusion coefficient to 2,6-DFBA diffusion coefficient was constrained to be 2.7 (or the ratio of $\frac{\phi}{b} \sqrt{D_{m}}$ was constrained to be $\sqrt{2.7}$ ). All other parameters were fixed according to the manner in which 
the field test was conducted (e.g., the injection concentration, injection duration, and time constants for mixing in the injection and production wellbores). Sensitivities of the fitted parameters to uncertainties in the I-to-FBA diffusion coefficient ratio are detailed in the "Discussion of Parameter Uncertainties" section.

After simultaneous fits were obtained for the iodide and 2,6-DFBA data sets, the PFBA data in well \#3 were fitted. Two fits were attempted to this data set, with the first using the smallest DFBA matrix diffusion coefficient deduced from the well \#1 to well \#3 response, and the second using the largest DFBA diffusion coefficient deduced from the well \#2 to well \#3 response. These two diffusion coefficient values were the extremes determined from the simultaneous fits to the iodide and DFBA data. The mass fraction (f), mean fluid residence time $(\tau)$, and Peclet number $(\mathrm{Pe})$ were adjusted to achieve the fits.

The microsphere responses in wells \#2 and \#3 were interpreted using the parameters $f, \tau$, and Pe derived from the appropriate solute responses, but with the matrix diffusion coefficient set equal to zero. The only adjustable parameter was a forward rate constant, which is mathematically equivalent to a filtration coefficient. A matrix diffusion coefficient of zero was considered reasonable because of the large size and small diffusivity of the microspheres relative to the solutes. Reverse filtration (detachment) was not included in the model because the second microsphere peaks were believed to be the result of hydrologic perturbations in the system rather than any fundamental transport behavior that would have occurred under steady flow conditions (see test results section). The differential equation used to describe microsphere transport in the fractures was

$$
\frac{\partial C}{\partial t}+V \frac{\partial C}{\partial x}-D \frac{\partial^{2} C}{\partial x^{2}}+k_{f} C=0
$$

where $\quad \mathrm{C}=$ colloid concentration, $\mathrm{mg} / \mathrm{L}$

$\mathrm{V}=$ flow velocity in fractures, $\mathrm{m} / \mathrm{hr}$

$\mathrm{D}=$ dispersion coefficient, $\mathrm{m}^{2} / \mathrm{hr}$

$\mathrm{k}_{\mathrm{f}}=$ filtration rate constant $(1 / \mathrm{hr})=\lambda \mathrm{V}$, where $\lambda=$ filtration coefficient $(1 / \mathrm{cm})$

$\mathrm{x}, \mathrm{t}=$ independent variables for distance and time, respectively.

Note that equation (1) is equivalent to equations (B1) and (B2) in Appendix B with $k_{\mathrm{fr}} \phi$, and $\alpha_{\mathrm{f}}$ equal to zero, and with $\left(\frac{\rho_{f}}{\eta}\right)$ and $\beta_{f}$ equal to 1 . Thus, the semi-analytical model is capable of duplicating the simple colloid transport expression given by equation (1).

\section{Results and Discussion of Model Fits}

Model fits to the cross-hole tracer data sets are shown in Figures 13, 14, and 15, corresponding to the data shown in Figures 3, 4, and 5, respectively. The model parameters associated with the fits are provided in Table 3.

Several points should be made regarding the fits and the deduced parameters before conclusions are drawn: 
- The lack of tailing in the fits to the microsphere data sets occurs because the microspheres were assumed to be irreversibly filtered. Only qualitative fits were obtained, with emphasis on the early portion of the data sets and matching of the recoveries. If reversible filtration (detachment) were allowed, a better fit could be obtained to the tails of the responses, although multiple detachment coefficients would be required to obtain good fits. The fact that the second microsphere peak was likely the result of flow perturbations rather than fundamental transport behavior under steady flow conditions discouraged attempts to fit the latter portion of the breakthrough curves.

- The two fits to the PFBA data in Figure 14 illustrate a fundamental limitation of obtaining transport parameter estimates from a single solute response: If the mass fraction is allowed to vary, the response can be fitted equally well assuming different values of the matrix diffusion coefficient, and each fit results in a different estimate of $\tau$ and Pe. Thus, the fit to a single solute response is nonunique. The two fits shown in Figure 14 were obtained using the smallest and largest values of the 2,6-DFBA diffusion coefficient obtained from any of the simultaneous fits to responses from well \#1 to \#3 and well \#1 to \#2.

- Only the first 1,000 hours of data from well \#1 to well $\# 2$ were fitted. This avoided the flow interruptions, which violate the steady-flow assumption of the semi-analytical model. The production rates in all wells were assumed to be constant with time (116 gpm for well \#3, and $5 \mathrm{gpm}$ for wells \#1 and \#2).

- The different values of $\tau$ and Pe reported in Table 3 for linear and radial flow were calculated to provide a measure of uncertainty in these parameters associated with uncertainty in the flow field. In a heterogeneous, confined aquifer, the flow velocity as a function of distance from a single production well is expected to vary between constant (linear) and having a 1/radius dependence (radial) (National Research Council, 1996). Thus, if we assume that the formation was reasonably confined, presenting the two sets of residence times and Peclet numbers in Table 3 is a way of bounding these parameter estimates as a result of flow field uncertainty. It should be noted that equally good fits can be obtained using either model, and both models predict exactly the same shape of curve if the values of the parameters are properly adjusted. The mathematical forms of the governing equations for both the linear and radial flow cases are presented in Appendix B.

- The values of the matrix diffusion coefficients in Table 3 should be interpreted with care. These values assume that the matrix porosity divided by the fracture half-aperture $(\phi / b)$ had an average value of 2 , which was arrived at by assuming an average matrix porosity of 0.1 and an average fracture aperture of $1 \mathrm{~mm}$ (half-aperture of $0.05 \mathrm{~cm}$ ). These values are reasonable for the rocks beneath Pahute Mesa, but there is a great deal of variability in matrix porosities and diffusion coefficients within even the $\sim 120$ - $\mathrm{m}$ interval tested in the FGE (Reimus et al., 1999a). Because the matrix diffusion coefficient is really part of the lumped parameter, $\frac{\phi}{b} \sqrt{D_{m}}$, its actual value will depend on what the true value of $\phi / b$ is. For example, if the value of $\phi / b$ is 1 instead of 2 , then the matrix diffusion coefficients providing the best fits would be a factor of 4 greater than the values given in Table 3 . For this reason, it is probably better to simply use the lumped parameter as a measure of matrix diffusion in the FGE system rather than the deduced value of $D_{m}$. 
- It follows from the previous bullet that, without knowing the actual lithologic units in which the tracers migrated in the FGE, there is a great deal of uncertainty associated with substituting laboratory-measured values of $\phi$ and $D_{m}$ into the lumped parameter $\frac{\phi}{b} \sqrt{D_{m}}$ to back-calculate effective fracture apertures (2b) in the FGE. For this reason, fracture apertures were not directly estimated.

- All solute fits were obtained assuming that the matrix was infinite in extent. That is, the distance between fractures was assumed to be great enough that solutes diffusing into the matrix did not feel the effects of solutes diffusing into the matrix from neighboring fractures. Fits were not improved significantly by assuming a finite matrix, although the extreme tails of the curves were sometimes slightly better fit under this assumption. However, this result was not considered convincing evidence that solutes were diffusing to the center of matrix blocks because tailing could also be explained by multiple flow pathways and the complicated flow field resulting from simultaneously pumping more than one well.

- The flow porosities reported in Table 3 were obtained directly from the estimates of the mean residence times in the system using the following formula, which assumes radial flow:

$$
\varepsilon=\frac{\mathrm{Q} \tau}{\pi\left(\mathrm{R}_{\mathrm{o}}^{2}-\mathrm{R}_{\mathrm{i}}^{2}\right) \mathrm{a}}
$$

where $\varepsilon=$ flow porosity,

$\mathrm{Q}=$ production rate, $\mathrm{m}^{3} / \mathrm{hr}$

$\tau=$ mean tracer residence time, $\mathrm{hr}$

$\mathrm{a}=$ formation thickness, $\mathrm{m}$

$\mathrm{R}_{\mathrm{o}}=$ distance from injection well to production well, $\mathrm{m}$, and

$R_{i}=$ distance from measurement well to production well, $m(=0$ if measurement well is production well).

The two flow porosities reported for the formation between wells \#1 and \#2 were calculated assuming (1) the $5 \mathrm{gpm}$ production rate from well \#2 was responsible for drawing the tracers to this well, and (2) the $116 \mathrm{gpm}$ production rate from well \#3 was responsible for drawing tracers to well \#2. Undoubtedly, the tracer movement was induced by both pumps, so the two resulting estimates should both be considered lower bounds.

- The time constants for tracer residence times in the injection wells were assumed to be $1 \mathrm{hr}^{-1}$ in both wells \#1 and \#2. This assumption is based on the fact that the volume of the screened intervals (including gravel pack) in the wells was approximately 1,500 gallons and the injection rate was approximately $20 \mathrm{gpm}$. If the volume is divided by the flow rate, the residence time is calculated to be 75 minutes, which is equivalent to a time constant of $0.8 \mathrm{hr}^{-1}$. This time constant would account for about $75 \%$ of the injectate solution, as the injection volume was approximately 6,000 gallons. However, the tracer solution remaining in the interval after injection did not enter the formation at this rate. The discrete bailer data prior to pumpback of the injection wells was used to estimate the rate at which residual tracer solution left the wellbore. If a well-mixed region is assumed, the decrease in tracer concentration will follow an exponential decay, and the following equation can be used to estimate the time constant: 


$$
k=\frac{\ln C_{0}-\ln C}{\Delta t}
$$

where $\quad \mathrm{k}=$ time constant, $\mathrm{hr}^{-1}$

$\mathrm{C}=$ concentration in wellbore at end of interval $\Delta t$,

$\mathrm{C}_{\mathrm{o}}=$ initial concentration in wellbore, and

$\Delta \mathrm{t}=$ time interval, $\mathrm{hr}$.

Using the solute data from the discrete bailer samples prior to pumpback, the time constants calculated for well \#1 and well \#2 were $0.09 \mathrm{hr}^{-1}$ and $0.06 \mathrm{hr}^{-1}$, respectively. A time constant of $0.75 \mathrm{hr}^{-1}$ was used in the RELAP simulations because this represents a reasonable upper bound value (which forces tracer out of the wellbore at the maximum justifiable rate). However, simulations were also conducted using injection well time constants of $0.05 \mathrm{hr}^{-1}$ and $3.0 \mathrm{hr}^{-1}$ to determine the sensitivity of the fitted transport parameters to the value assumed. The results indicated that the fitted values were quite insensitive to the value of the time constant over this range (see next section). The time constant for the well $\# 3$ production wellbore was assumed to be $5 \mathrm{hr}^{-1}$ based on a $116 \mathrm{gpm}$ production rate and a 1,500 gallon interval volume. The well \#2 production wellbore time constant was assumed to be $0.2 \mathrm{hr}^{-1}$ based on a $5 \mathrm{gpm}$ production rate and a 1,500 gallon volume. Again, the fitted transport parameters were quite insensitive to these assumptions.

\section{Discussion of Parameter Uncertainties}

Uncertainties in the parameter estimates given in Table 3 are related to scatter in the data (primarily due to analytical errors) as well as the goodness and the uniqueness of the curve fits. Parameter uncertainty due to data scatter can generally be quantified by statistical measures such as "95\% confidence intervals" (Draper and Smith, 1981). This uncertainty is expected to be relatively small given the smoothness of the breakthrough curve data, but we do not address it formally here. Goodness-of-fit errors are apparent from visual comparisons of the actual data and the fitted curves. The best way to analyze these errors is to plot residuals (differences between the data and the modeling predictions) and use standard techniques to analyze trends in the residuals (Draper and Smith, 1981). This exercise was also not addressed formally in this report. Uniqueness-of-fit uncertainties are related to the ability of different combinations of model parameters to explain data sets almost equally well. In statistical terminology, this situation occurs when there is a complex response surface with multiple minima. Although we did not conduct an exhaustive uniqueness-of-fit study, we did conduct an abbreviated sensitivity analysis by independently varying two input parameters that we felt had significant uncertainty: the iodide-to-FBA diffusion coefficient ratio, and the injection well residence time. Three different values were assumed for each parameter; a lower bound, a best estimate, and an upper bound. These values were $2.5,2.7$, and 3.0, respectively, for the diffusion coefficient ratio, and $0.33,1.25$, and $20 \mathrm{hrs}$, respectively, for the injection well residence time.

Table 4 gives fitted (or deduced in the case of flow porosity) transport parameter estimates for all possible combinations of these input parameter values. It is apparent that the fitted parameters of Table 4 are not extremely sensitive to the input parameters over the range of 
values studied. As mentioned in the previous section, we also fitted the data sets assuming both radial and linear flow, as these two assumptions can lead to different values of mean residence time (and flow porosity) and Peclet number. Table 3 shows that the sensitivity to the flow-field assumption was as great as the sensitivity to the parameters varied in Table 4. Intuitively, we expect that the range of fitted parameter values given in Tables 3 and 4 is greater than any $95 \%$ confidence interval that would be obtained from standard statistical techniques (because of the smoothness of the tracer data).

\section{Conclusions}

The following conclusions can be drawn from the analysis of the BULLION FGE tracer data and the resulting parameter values listed in Table 3:

- Matrix diffusion is evident in the well \#1 to \#2 tracer responses and the well \#1 to \#3 responses, although its magnitude, as reflected in the lumped parameter, $\frac{\phi}{b} \sqrt{D_{m}}$, is somewhat smaller than values obtained from field tracer testing for the Yucca Mountain Project (Reimus et al., 1999b). The results nevertheless support a dual-porosity conceptual model for transport in the saturated zone. Matrix diffusion cannot be definitively established in the well \#2 to \#3 responses because there was only one solute (and the microspheres were strongly attenuated, which prevented them from being assumed to be conservative tracers). The fact that there was more apparent matrix diffusion between well \#1 and \#2 than between well \#1 and \#3 could be attributed to either greater matrix porosities or smaller average fracture apertures between the first two wells. However, it is also possible that there is a time dependence of matrix diffusion, with decreasing rates of mass transfer into the matrix as time scales increase. This apparent time dependence was also observed in Yucca Mountain field tracer testing (Reimus et al., 1999b), and it could suggest that multiple matrix diffusion rates (Haggerty and Gorelick, 1995) are important over long time scales or that interconnected porosity, and hence diffusion coefficients in the matrix, decrease with distance into the matrix (away from fractures). It is also possible that some of what appeared to be matrix diffusion was actually diffusion into stagnant water along the rough fracture walls or within the fractures themselves (occurring as a result of tracers diffusing out of high flow rate channels and into low flow zones), rather than into the matrix proper. These possibilities have important implications for saturated zone performance assessments and merit further study because, if valid, they would suggest that matrix diffusion might be overestimated in short-duration tracer experiments.

- The relatively low predicted mass fractions of tracers contributing to the breakthrough curves indicate that matrix diffusion cannot account for the low observed tracer recoveries. The difference between the predicted mass fractions in Table 3 (or 4 ) and the actual fractional recoveries in Table 2 is the predicted mass fraction lost to the matrix.

- The Peclet numbers and longitudinal dispersivities are reasonably consistent in each of the injection-production well combinations. Furthermore, the dispersivities are consistent with relationships reported in the literature for dispersivity vs. length scale. Figure 16 shows where the longitudinal dispersivity values deduced from the BULLION FGE fall on a plot of 
dispersivity vs. length scale prepared by Neuman (1990). It is apparent that the longitudinal dispersivity values from the FGE are at the upper $95 \%$ confidence bounds defined by Neuman. The implication is that there is nothing unique about dispersion in the saturated zone beneath Pahute Mesa that suggests that such a published dispersivity-vs.-scale relationship cannot be used to estimate dispersivities over much larger scales in performance/risk assessment calculations.

- The relatively low effective flow porosities in Tables 3 and 4 are all reasonably consistent with the current understanding of the hydrogeology beneath Pahute Mesa. These porosities support a dual-porosity conceptual transport model, as matrix porosities are typically much greater than the flow porosities in Tables 3 and 4.

- The microsphere filtration rate constants, $\mathrm{k}_{\mathrm{f}}$, and filtration coefficients, $\lambda$, indicate that significant filtration occurred in the flow system, and that the filtration rate was approximately the same (within a factor of 2) between each injection-production well combination. The greater-than-predicted tailing of the microsphere data suggests that there is either a significant reverse filtration (detachment) rate, or that there were separate flow pathways for the late-arriving spheres that had smaller effective filtration coefficients. In either case, it can be concluded that although the microspheres were significantly attenuated in the flow system relative to the conservative solutes, a fraction of them still transported quite efficiently through the system. As discussed in the results section, the second peaks of microspheres in well \#3 are attributed to the flow interruption and flow reversal in this well. This serendipitous result could have important implications for colloid transport and colloidfacilitated radionuclide transport in the saturated zone, as it suggests that natural flow perturbations could possibly mobilize previously filtered colloids. The early arrival of microspheres in the well \#1-to-\#3 response relative to the model fits can possibly be attributed to a portion of the microspheres remaining in high-velocity streamlines within the fractures for extended periods of time, which would violate the model assumption of no concentration gradients across the fracture apertures. Because the microspheres are much less diffusive than the solutes, they are expected to remain in high velocity streamlines much longer than the solutes, and consequently a small percentage of them can be expected to move rapidly through the fractures. This earlier-than-predicted arrival of microspheres was also observed in Yucca Mountain Project field tracer testing (Reimus et al., 1999b).

We consider the RELAP modeling of the FGE tracer responses to be a relatively simple approach to interpreting the data. This approach involves a minimum number of adjustable parameters and assumes no spatial heterogeneity, which we believe is consistent with the limited knowledge of flow system geometry and heterogeneity. We recognize that there is much room for revisiting the analyses using more sophisticated modeling tools and introducing more system complexity, particularly as more site-specific information becomes available. The results of the semi-analytical modeling can be used to help guide numerical modeling efforts that might provide answers to some of the questions not answered by the semi-analytical analyses (e.g., why are the tracer recoveries so low?).

In summary, the preliminary interpretation of the BULLION FGE tracer responses supports the concept of using a dual-porosity transport model to describe radionuclide migration in the saturated zone beneath Pahute Mesa. Matrix diffusion is evident in the cross-hole solute 
tracer responses, and the longitudinal dispersivities deduced from the responses are reasonably consistent with literature values. The microsphere responses indicate significant colloid filtration/attenuation over the distance and time scales of the FGE. However, the extended tails of the microsphere responses and the second peak(s) at well \#3 (tentatively attributed to a flow interruption/reversal in this well) also suggest significant reversibility of filtration.

\section{Acknowledgments}

Several organizations were involved in the BULLION FGE, including IT Corporation, HSI/Geotrans, Desert Research Institute, University of Nevada Las Vegas/Harry Reid Center, Bechtel Nevada, Lawrence Livermore National Laboratory, and Los Alamos National Laboratory. Too many individuals were involved to acknowledge them all by name, and any attempt to do so would undoubtedly leave someone out. However, we wish to single out Bill Fryer and Bob Curiale of IT Corporation for helping coordinate the microsphere portion of the FGE and for providing the solute data for this report. Robert Habbersett of Los Alamos National Laboratory provided invaluable assistance with the flow cytometry measurements of microsphere concentrations. This work was conducted under contract with the United States Department of Energy (DOE). Los Alamos National Laboratory is operated by the University of California for the DOE under Contract W-7405-ENG-36. 


\section{References}

Arya, A., Dispersion and reservoir heterogeneity, Ph.D. dissertation, University of Texas at Austin, 1986.

Becker, M. W., Tracer Tests in a Fractured Rock and their First Passage Time Mathematical Models, Ph.D. dissertation, University of Texas at Austin, 1996.

Becker, M. W., Reimus, P. W., and Vilks, P., Microspheres detected by flow cytometry and their application as groundwater tracers in fractured rock, Groundwater, 37(3), 387-395, 1999.

Benson, C. F. and Bowman, R. S., Tri- and tetrafluorobenzoates as nonreactive tracers in soil and groundwater, Soil Science Society of America Journal, 58, 1,123-1,129, 1994.

Blankennagel, R. K. and Weir, J. E, Jr., Geohydrology of the Eastern Part of Pahute Mesa, Nevada Test Site, Nye County, Nevada, Geological Survey Professional Paper 712-B., United States Government Printing Office, Washington, 1973.

Churchill, R. V., Operational Mathematics, 2nd ed., McGraw-Hill, New York, 1958.

Draper, N. R. and Smith, H., Applied Regression Analysis, 2nd ed., John Wiley and Sons, New York, 1981.

Drellack, S. L. and Prothro, L. B., Descriptive Narrative for the Hydrogeologic Model of Western and Central Pahute Mesa Corrective Action Units, Bechtel Nevada interim report, 1997.

Gelhar, L. W., A. Mantoglou, C. Welty, and K. R. Rehfeldt, A review of field-scale physical solute transport processes in saturated and unsaturated porous media, Electric Power Research Institute report EPRI EA-4190, Project 2485-5, Electric Power Research Institute, Palo Alto, California, Aug. 1985.

Grisak, G. E. and Pickens, J. F., Solute transport through fractured media, 1: The effect of matrix diffusion, Water Resources Research, 16(4), 719-730, 1980.

Haggerty, R. and Gorelick, S. M., Multiple-rate mass transfer for modeling diffusion and surface reactions in a media with pore-scale heterogeneity, Water Resources Research, 31(10), 2,383-2,400, 1995.

IT Corporation, Criteria for the Forced-Gradient Experiment at the BULLION Event Location, IT Corporation report ITLV/10972-182, 1996.

IT Corporation, BULLION Forced-Gradient Experiment Implementation Plan, IT Corporation report ITLV/10972-195, 1997. 
IT Corporation, Report and Analysis of the BULLION Forced-Gradient Experiment, IT Corporation report ITLV/13052-042 (also available as Department of Energy report DOE/NV/13052-042), 1998.

Lallemand-Barres, A., and P. Peaudecerf, Recherche des relations entre la valeur de la dispersivité macroscopique d'un aquifère, ses autres caractéristiques et les conditions de mesure, Bulletin du Bureau de Recherches Geologiques et Minieres, Sect. 3, 4, 1978.

Lessoff, S. C. and Konikow, L. F., Ambiguity in measuring matrix diffusion with single-well injection/recovery tracer tests, Groundwater, 35(1), 166-176, 1997.

Maloszewski, P. and Zuber, A., Interpretation of artificial and environmental tracers in fissured rocks with a porous matrix, in Isotope Hydrology, International Atomic Energy Agency (IAEA), Vienna, Austria, pp. 635-651, 1983.

Maloszewski, P. and Zuber, A., On the theory of tracer experiments in fissured rocks with a porous matrix, Journal of Hydrology, 79, 333-358, 1985.

Maloszewski, P. and Zuber, A., Influence of matrix diffusion and exchange reactions on radiocarbon ages in fissured carbonate aquifers, Water Resources Research, 27(8), 1,937$1,945,1991$.

Meigs, L. C., Beuheim, R. L., McCord, J. T., Tsang, Y. W., and Haggerty, R., Design, modelling, and current interpretations of the $\mathrm{H}-19$ and $\mathrm{H}-11$ tracer tests at the WIPP Site, for publication in Field Tracer Transport Experiments, proceedings of the first GEOTRAP Workshop, Cologne, Germany, August 28-30, 1996.

Moench, A. F., Convergent radial dispersion in a double-porosity aquifer with fracture skin: Analytical solution and application to a field experiment in fractured chalk, Water Resources Research, 31(8), 1,823-1,835, 1995.

National Research Council, Rock Fractures and Fluid Flow: Contemporary Understanding and Applications, National Academy Press, Washington, D.C., 1996.

Neretnieks, I., Diffusion in the rock matrix: An important factor in radionuclide migration?, Journal of Geophysical Research, 85(B8), 4,379-4,397, 1980.

Neuman, S. P., Universal scaling of hydraulic conductivities and dispersivities in geologic media, Water Resources Research, 26(8), 1,749-1,758, 1990.

Pickens, J. F., and G. E. Grisak, Scale-dependent dispersion in a stratified granular aquifer, Water Resources Research, 17(4), 1,191-1,211, 1981.

Reimus, P. W., The Use of Synthetic Colloids in Tracer Transport Experiments in Saturated Rock Fractures, Los Alamos National Laboratory report LA-13004-T (also Ph.D. dissertation, University of New Mexico), Los Alamos National Laboratory, Los Alamos, NM, 1995. 
Reimus, P. W., Use of a flow cytometer to determine particle concentrations in solution, Los Alamos National Laboratory standard operating procedure LANL-CST-04, Rev. 0, 1997.

Reimus, P. W., Haga, M. J., Humphrey, A. R., Anghel, I., Counce, D., Callahan, T. J., and Ware, S. D., Laboratory Experiments to Support Interpretation of the BULLION Forced-Gradient Experiment: Update Report, Underground Test Area (UGTA) Project Report (draft), Los Alamos National Laboratory, Los Alamos, NM, 1999a.

Reimus, P. W., Adams, A., Haga, M. J., Humphrey, A. R., Callahan, T. J., Anghel, I., and Counce, D., Results and Interpretation of Hydraulic and Tracer Testing in the Prow Pass Tuff at the C-Holes, Yucca Mountain Site Characterization Project Milestone Report SP32E7M4, Los Alamos National Laboratory, Los Alamos, NM, $1999 \mathrm{~b}$.

Steinkamp, J. A., Habbersett, R. C., and Hiebert, R. D., Improved multilaser/ multiparameter flow cytometer for analysis and sorting of cells and particles, Review of Scientific Instruments, 62(11), 2,751-2,764, 1991.

Tang, D. H., Frind, E. O., and Sudicky, E. A., Contaminant transport in a fractured porous media: Analytical solution for a single fracture, Water Resources Research, 17(3), 555-564, 1981.

Wan, J. and Wilson, J. L., Colloid transport in unsaturated porous media, Water Resources Research, 30(4), 857-864, 1994. 


\section{Tables}

Table 1. Injection masses/numbers of tracers in each injection well.

\begin{tabular}{|c|c|c|}
\hline Tracer & Well \#1 & Well \#2 \\
\hline Iodide (as NaI) & $48.26 \mathrm{~kg}(57 \mathrm{~kg}$ of $\mathrm{NaI})$ & $\overline{---}$ \\
\hline 2,6-DFBA & $57 \mathrm{~kg}$ & $\overline{-\cdots}$ \\
\hline PFBA & -- & $57 \mathrm{~kg}$ \\
\hline Red Microspheres & $15 \times 10^{15}$ spheres $^{(a)}$ & $\cdots$ \\
\hline Yellow Microspheres & $\cdots$ & $1.68 \times 10^{15}$ spheres $^{(a)}$ \\
\hline
\end{tabular}

Table 2. Fractional recoveries of tracers in each well.

\begin{tabular}{ccccc}
\hline Tracer & Well \#1 & Well \#2 & Well \#3 & Total \\
\hline Iodide & 0.018 & 0.0042 & 0.077 & 0.099 \\
\hline 2,6-DFBA & 0.017 & 0.0045 & 0.087 & 0.109 \\
\hline PFBA & --- & 0.061 & 0.252 & 0.313 \\
\hline Red Spheres & 0.017 & 0.0022 & 0.0055 & 0.025 \\
\hline Yellow Spheres & --- & 0.073 & 0.012 & 0.085 \\
\hline
\end{tabular}


Table 3. Transport parameters deduced from fits to cross-hole tracer responses. The simultaneous fits to the Well 1-3 and the Well 1-2 data assume an iodide-to-FBA diffusion coefficient ratio of 2.7 (iodide larger). See Table 4 for sensitivity of parameters to this assumption.

\begin{tabular}{|c|c|c|c|c|}
\hline Parameter & Well 1-3 & Well 1-2 & Well 2-3 ${ }^{(a)}$ & Well 2-3 \\
\hline Mass Fraction $^{(\mathrm{c})}$ & $0.19-0.20$ & 0.005 & $0.50-0.54$ & $0.65-66$ \\
\hline Linear $\tau, \mathrm{hrs}$ & 1,950 & 300 & 2,325 & 1,825 \\
\hline Linear Pe (dispersivity, m) & $4.5(29)$ & $2.75(15.3)$ & $2.0(44.5)$ & $2.5(35.6)$ \\
\hline Radial $\tau$, hrs & 1,600 & 210 & 1,675 & 1,275 \\
\hline Radial Pe (dispersivity, $\mathrm{m}$ ) & $6.25(21)$ & $4.5(9.3)$ & $3.0(29.7)$ & $4.0(22.3)$ \\
\hline Lin. Flow Porosity & 0.0080 & $0.0005(0.0023)^{(\mathrm{d})}$ & 0.021 & 0.016 \\
\hline Rad. Flow Porosity & 0.0066 & $0.00036(0.0016)^{(\mathrm{d})}$ & 0.015 & 0.011 \\
\hline Iodide $\frac{\phi}{b} \sqrt{D_{m}}, \sec ^{-1 / 2}$ & 0.00024 & 0.00049 & -- & -- \\
\hline FBA $\frac{\phi}{b} \sqrt{D_{m}}, \sec ^{-1 / 2}$ & 0.00015 & 0.00030 & 0.00013 & 0.00042 \\
\hline Iodide $\mathrm{D}_{\mathrm{m}}, \mathrm{cm}^{2} / \mathrm{sec}^{(\mathrm{e})}$ & $1.5 \times 10^{-8}$ & $6.0 \times 10^{-8}$ & -- & --- \\
\hline FBA D $D_{\mathrm{m}}, \mathrm{cm}^{2} / \mathrm{sec}^{(e)}$ & $0.555 \times 10^{-8}$ & $2.22 \times 10^{-8}$ & $0.43 \times 10^{-8}$ & $4.4 \times 10^{-8}$ \\
\hline Sphere $\mathrm{k}_{\mathrm{f}}, \mathrm{hr}^{-1(t)}$ & 0.0040 & 0.0047 & 0.0060 & 0.0076 \\
\hline Sphere $\lambda, \mathrm{cm}^{-1(f)}$ & 0.0006 & 0.00034 & 0.0016 & 0.0016 \\
\hline
\end{tabular}

(a) Assumes $\frac{\phi}{b} \sqrt{D_{m}}$ for PFBA is equal to smallest value of $\frac{\phi}{b} \sqrt{D_{m}}$ for 2,6-DFBA between wells $\# 1$ and \#3 (from sensitivity analyses described in text and summarized in Table 4).

(b) Assumes $\frac{\phi}{b} \sqrt{D_{m}}$ for PFBA is equal to largest value of $\frac{\phi}{b} \sqrt{D_{m}}$ for 2,6-DFBA between wells \#1 and \#2 (from sensitivity analyses described in text and summarized in Table 4).

(c)Range of best-fit values assuming linear or radial flow.

(d) First value assumes that tracer movement between wells \#1 and \#2 was due to pumping well \#2; value in parentheses assumes tracer movement due to pumping well \#3. Values were calculated using equation (2) with linear or radial $\tau$ listed higher in table.

${ }^{(e)} D_{m}$ values calculated from $\frac{\phi}{b} \sqrt{D_{m}}$ assuming $\phi / b=2.0$.

${ }^{(f)}$ Relationship between $k_{f}$ and $\lambda$ is $k_{f}=\lambda V$, where $V$ is average linear velocity. 
Table 4. Well 1-3 and Well 1-2 solute transport parameter estimates as a function of assumed diffusion coefficient ratios and injection wellbore residence times (linear flow).

\begin{tabular}{|c|c|c|c|c|c|c|c|}
\hline \multirow{2}{*}{\multicolumn{2}{|c|}{$\begin{array}{c}\text { Parameter / } \\
\text { I-to-FBA } D_{m} \text { Ratio }\end{array}$}} & \multicolumn{3}{|c|}{ Well 1-3 (Inj. WB Res. Time) } & \multicolumn{3}{|c|}{ Well 1-2 (Inj. WB Res. Time) } \\
\hline & & $20-\mathrm{hr}$ & $1.25-\mathrm{hr}$ & $0.33-\mathrm{hr}$ & $20-\mathrm{hr}$ & $1.25-\mathrm{hr}$ & $0.33-\mathrm{hr}$ \\
\hline \multirow{3}{*}{ Mass Fraction $^{(a)}$} & 2.5 & 0.20 & 0.19 & 0.20 & 0.0055 & 0.005 & 0.005 \\
\hline & 2.7 & 0.19 & 0.19 & 0.19 & 0.00525 & 0.005 & 0.005 \\
\hline & 3.0 & 0.19 & 0.19 & 0.18 & 0.00525 & 0.005 & 0.005 \\
\hline \multirow{3}{*}{ Linear $\tau$, hrs } & 2.5 & 1,950 & 1,950 & 1,950 & 330 & 300 & 280 \\
\hline & 2.7 & 1,975 & 1,950 & 1,950 & 340 & 300 & 280 \\
\hline & 3.0 & 1,975 & 2,025 & 1,900 & 340 & 300 & 300 \\
\hline \multirow{3}{*}{ Linear Pe } & 2.5 & 4.25 & 4.5 & 4.5 & 1.75 & 2.75 & 3.0 \\
\hline & 2.7 & 4.25 & 4.5 & 4.5 & 1.75 & 2.75 & 3.0 \\
\hline & 3.0 & 4.25 & 4.25 & 4.75 & 1.75 & 2.75 & 2.75 \\
\hline \multirow{3}{*}{ Flow Porosity ${ }^{(b)}$} & 2.5 & 0.0080 & 0.0080 & 0.0080 & 0.00056 & 0.00051 & 0.00048 \\
\hline & 2.7 & 0.0082 & 0.0080 & 0.0080 & 0.00058 & 0.00051 & 0.00048 \\
\hline & 3.0 & 0.0082 & 0.0084 & 0.0079 & 0.00058 & 0.00051 & 0.00051 \\
\hline \multirow{3}{*}{$\mathrm{I} \frac{\phi}{\mathrm{b}} \sqrt{\mathrm{D}_{\mathrm{m}}}, \sec ^{-1 / 2}$} & 2.5 & 0.00028 & 0.00024 & 0.00027 & 0.00066 & 0.00049 & 0.0006 \\
\hline & 2.7 & 0.00024 & 0.00024 & 0.00024 & 0.00053 & 0.00049 & 0.0006 \\
\hline & 3.0 & 0.00024 & 0.00023 & 0.00023 & 0.00053 & 0.00053 & 0.00053 \\
\hline \multirow{3}{*}{\multicolumn{2}{|c|}{ 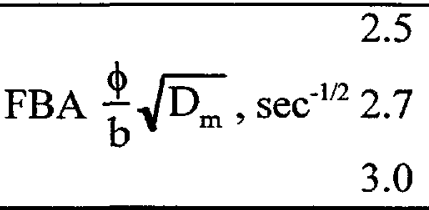 }} & 0.00017 & 0.00015 & 0.00017 & 0.00042 & 0.00031 & 0.00038 \\
\hline & & 0.00014 & 0.00015 & 0.00015 & 0.00032 & 0.00030 & 0.00037 \\
\hline & & 0.00014 & 0.00013 & 0.00013 & 0.00032 & 0.00031 & 0.00031 \\
\hline
\end{tabular}

(a) Calculated mass fraction contributes to response, not the actual mass recovery.

(b) For Well 1-2 responses, it was assumed that all tracer movement was due to pumping Well \#2 (relative variability would be the same, but absolute porosities would change, if tracer movement were assumed to be due to pumping Well \#3). 


\section{Figures}

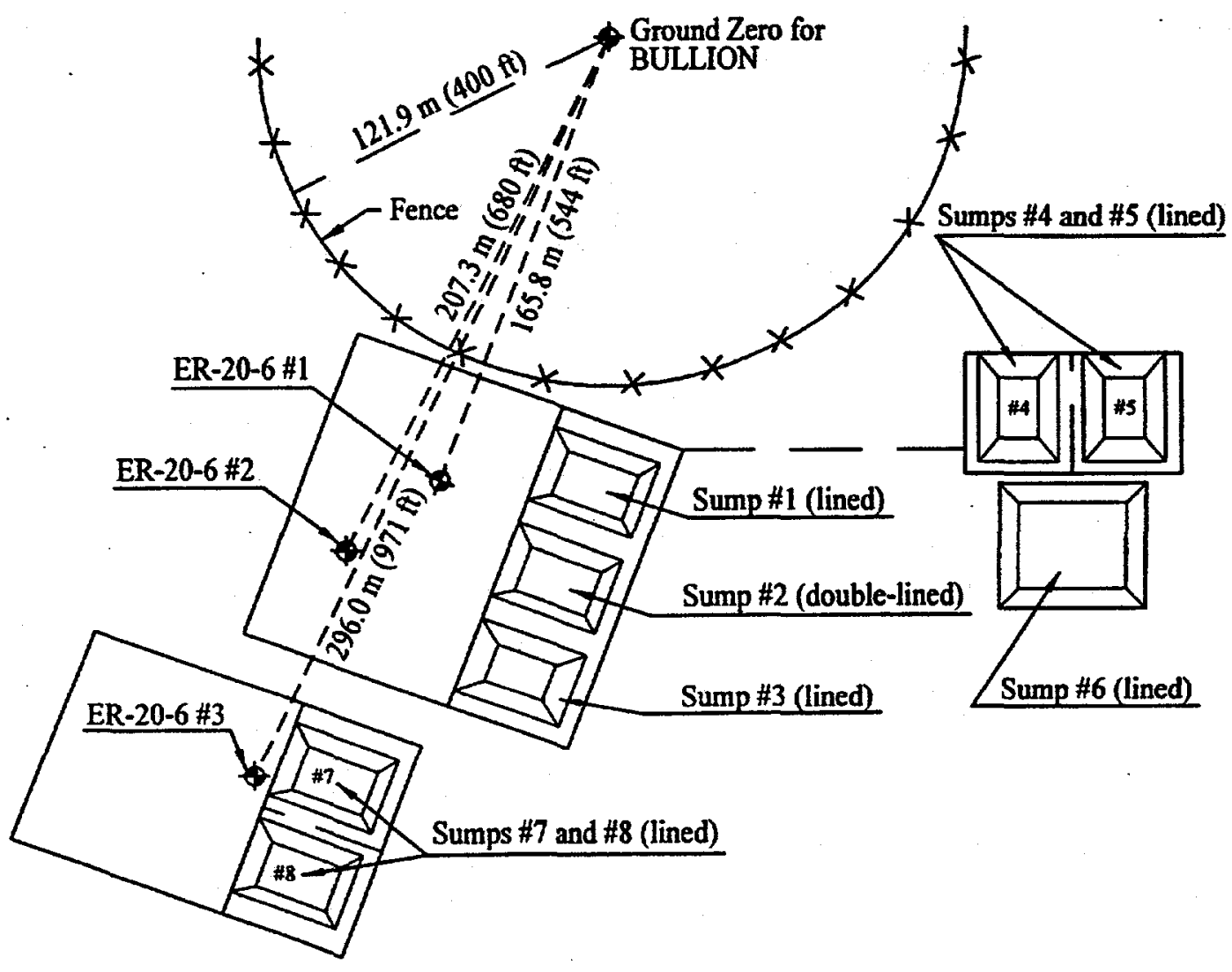

Figure 1. Schematic showing layout of wells used for the BULLION forced-gradient experiment (taken from IT, 1998). 


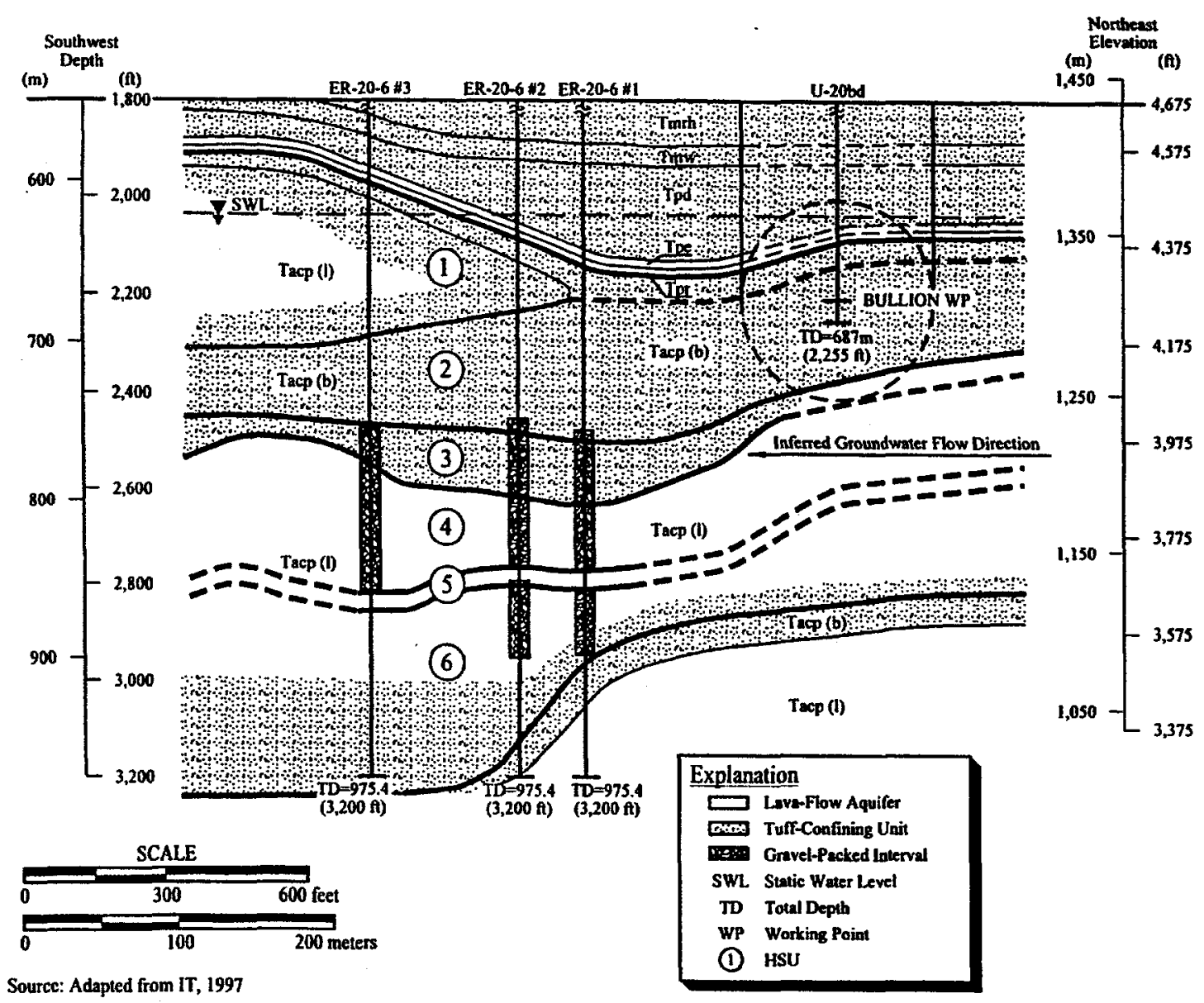

Figure 2. Hydrogeologic cross-section through the wells used for the BULLION FGE (taken from IT, 1998). Refer to IT (1996) and Drellack and Prothro (1997) for an explanation of the hydrogeologic unit abbreviations. The hydrostratigraphic units (HSUs) are defined in IT (1998) as (1) uppermost lava flow aquifer and bedded tuff, (2) upper zeolitic bedded tuff, (3) altered (zeolitic) middle lava, (4) middle lava flow aquifer, (5) lower-permeability lava zone, and (6) lower lava flow aquifer. 


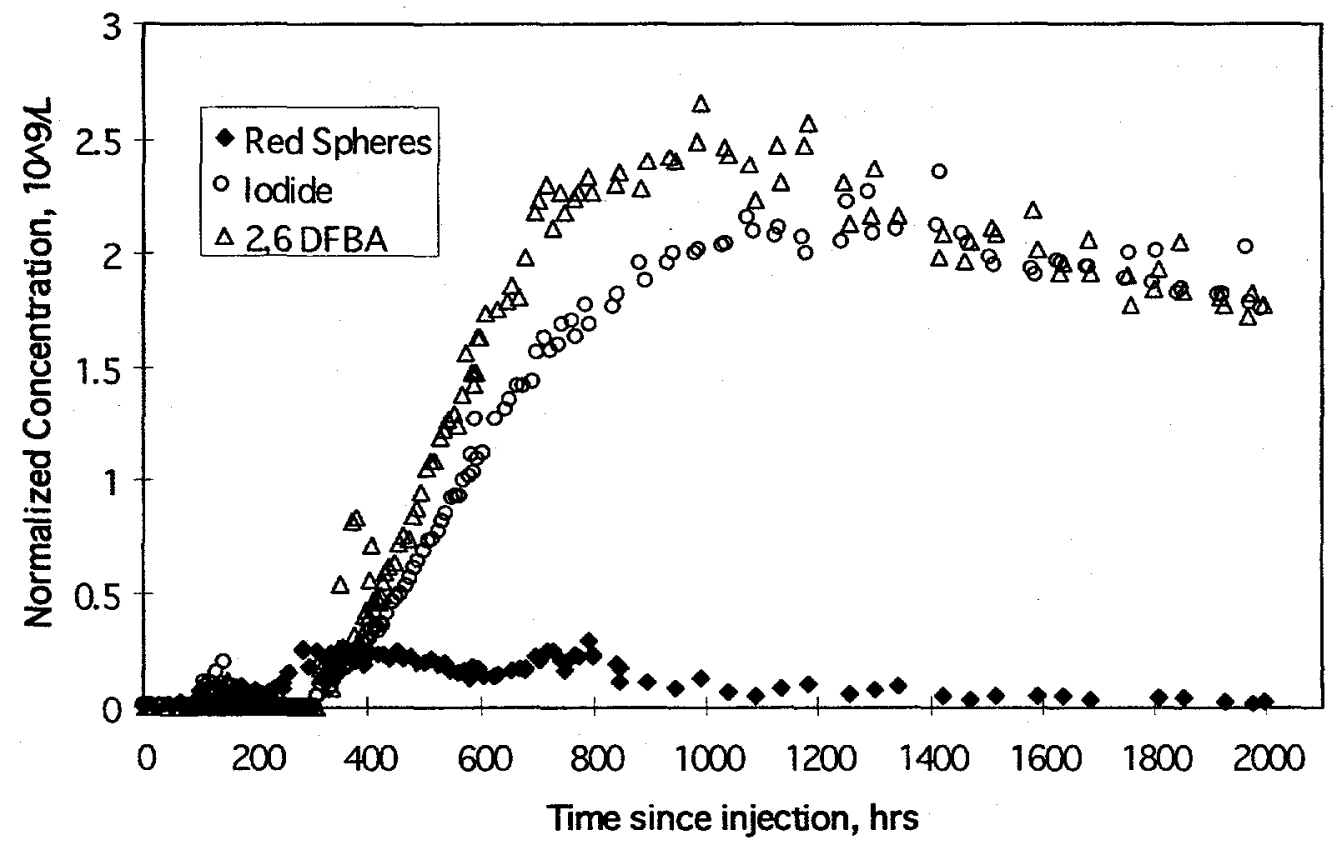

Figure 3. Responses of tracers injected into well \#1 at well \#3. Solute data courtesy of IT Corporation.

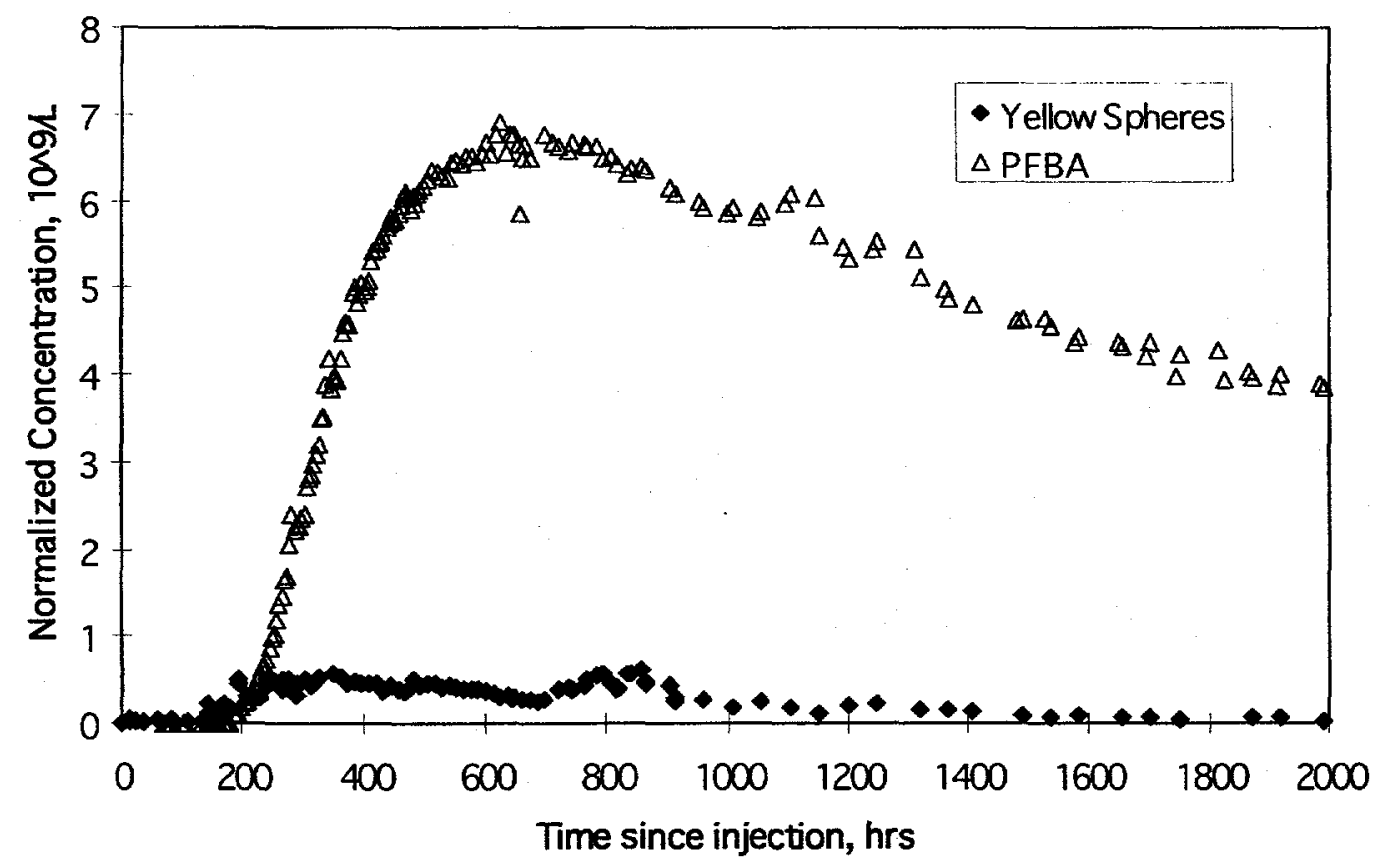

Figure 4. Responses of tracers injected into well \#2 at well \#3. Solute data courtesy of IT Corporation. 


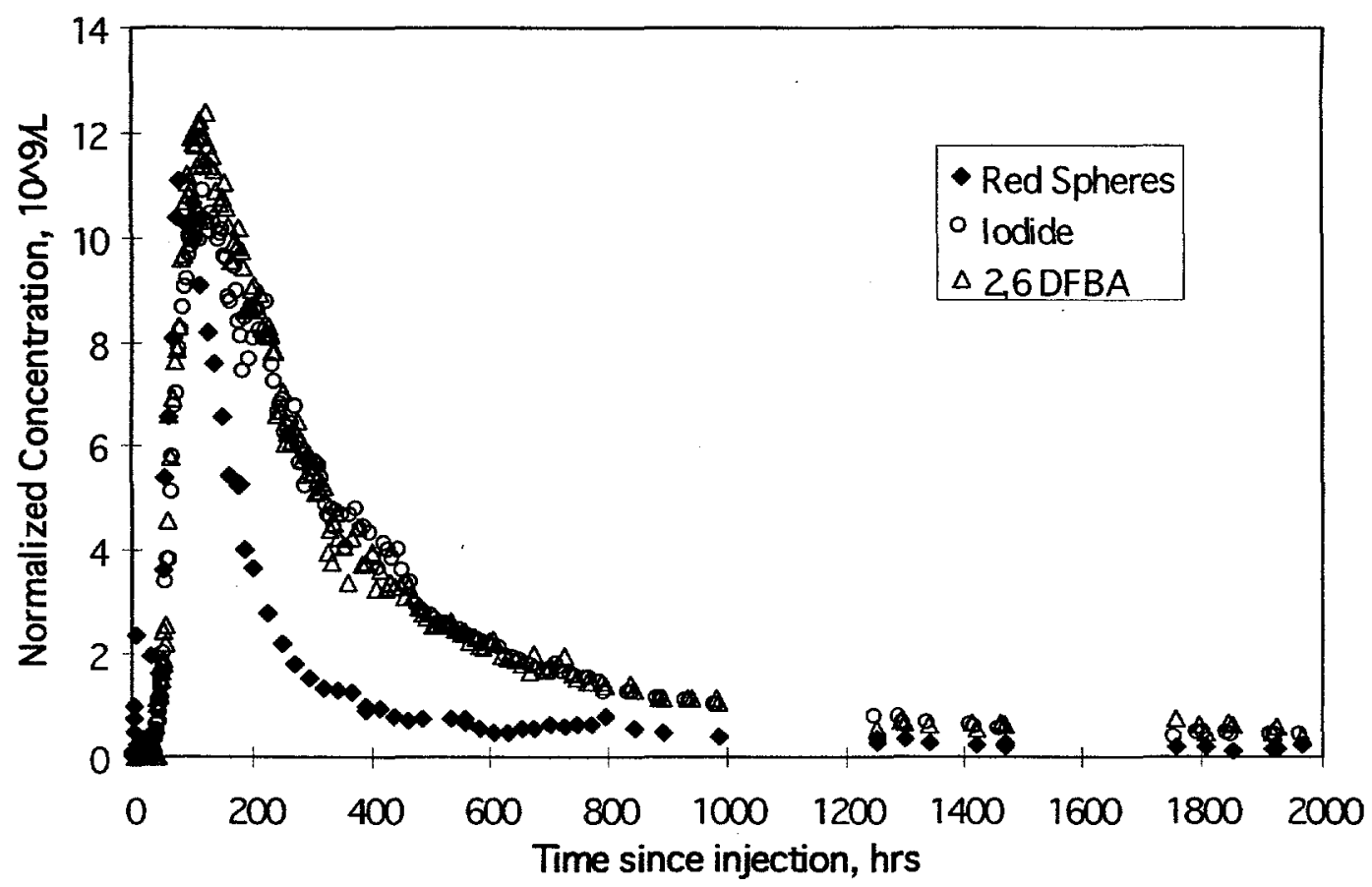

Figure 5. Responses of tracers injected into well \#1 at well \#2. Solute data courtesy of IT Corporation. Gaps in data correspond to periods when pumping was stopped.

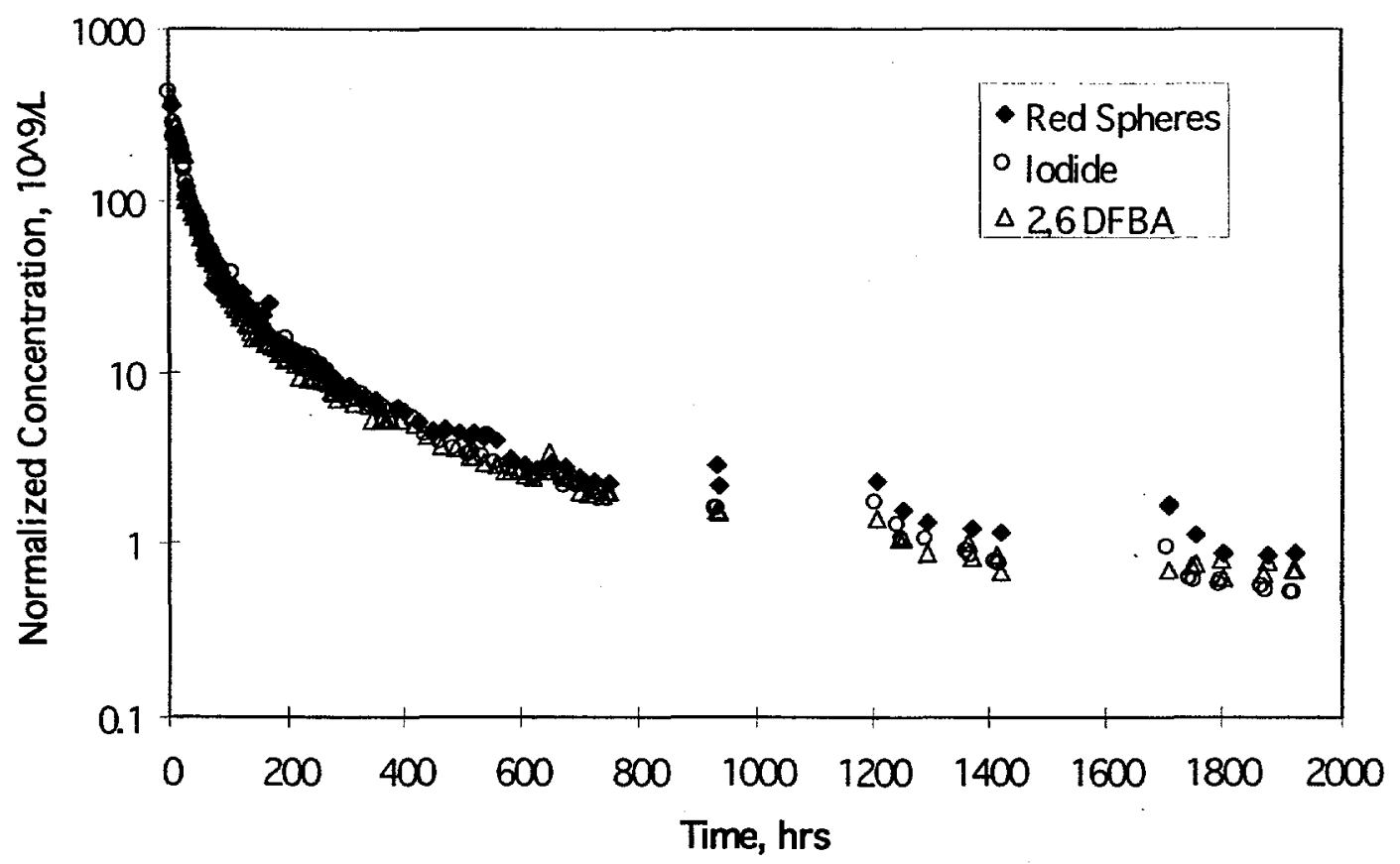

Figure 6. Pumpback responses of tracers injected into well \#1. Solute data courtesy of IT Corporation. Gaps in data correspond to periods when pumping was stopped. 


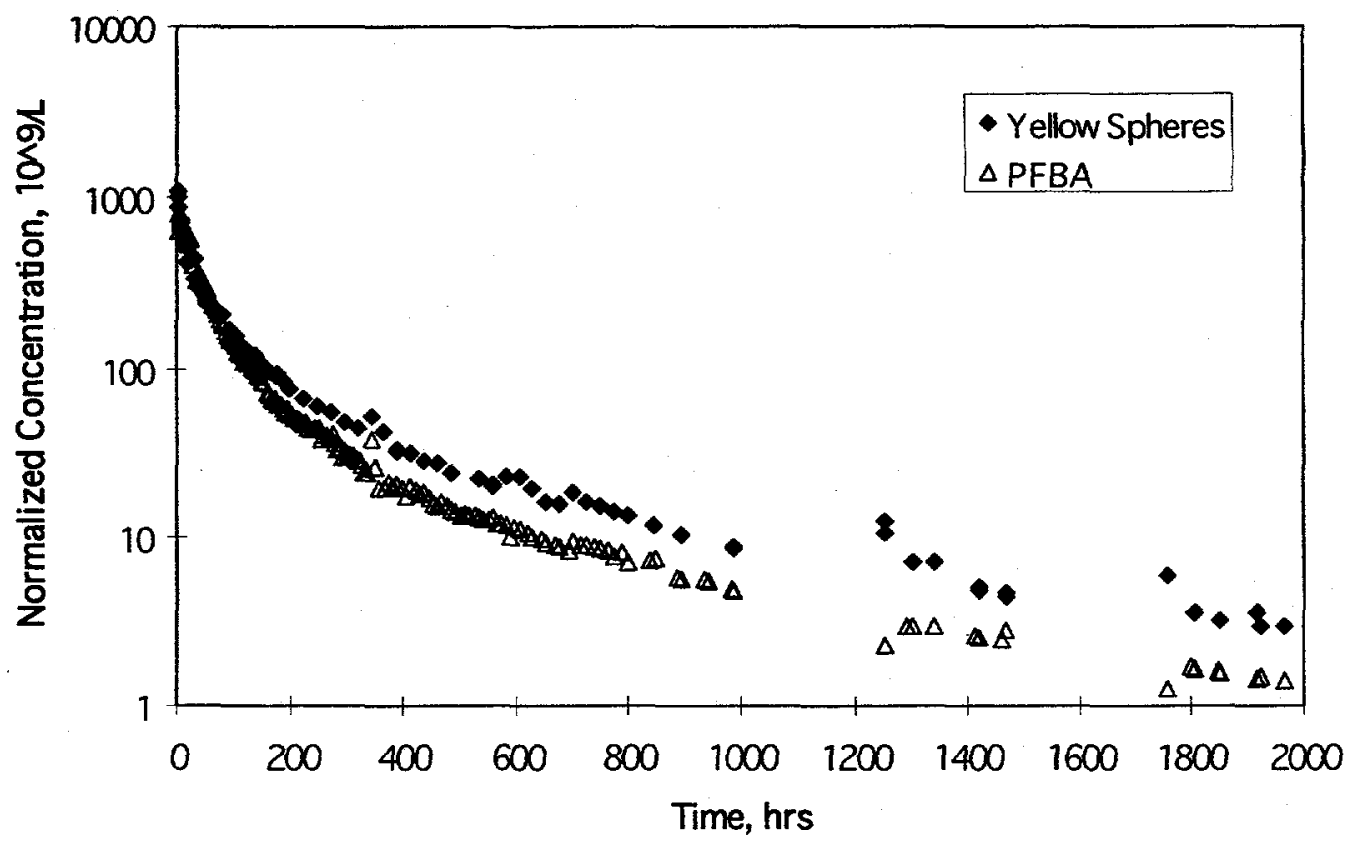

Figure 7. Pumpback responses of tracers injected into well \#2. Solute data courtesy of IT Corporation. Gaps in data correspond to periods when pumping was stopped.

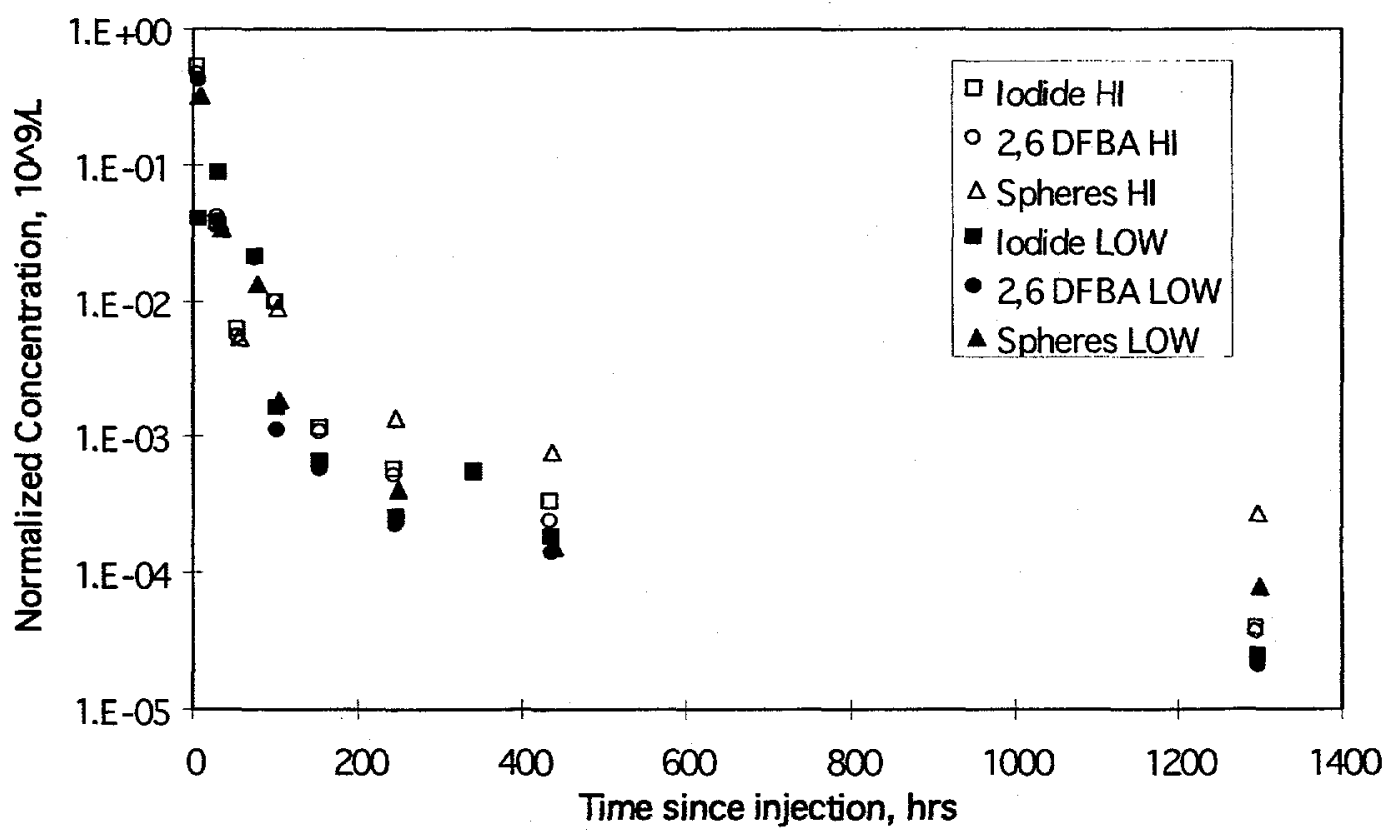

Figure 8. Tracer concentrations (normalized to injection concentrations) in discrete bailer samples from well \#1. "HI" refers to upper part of injection interval, and "LOW" refers to lower part of interval. Solute data courtesy of IT Corporation. 


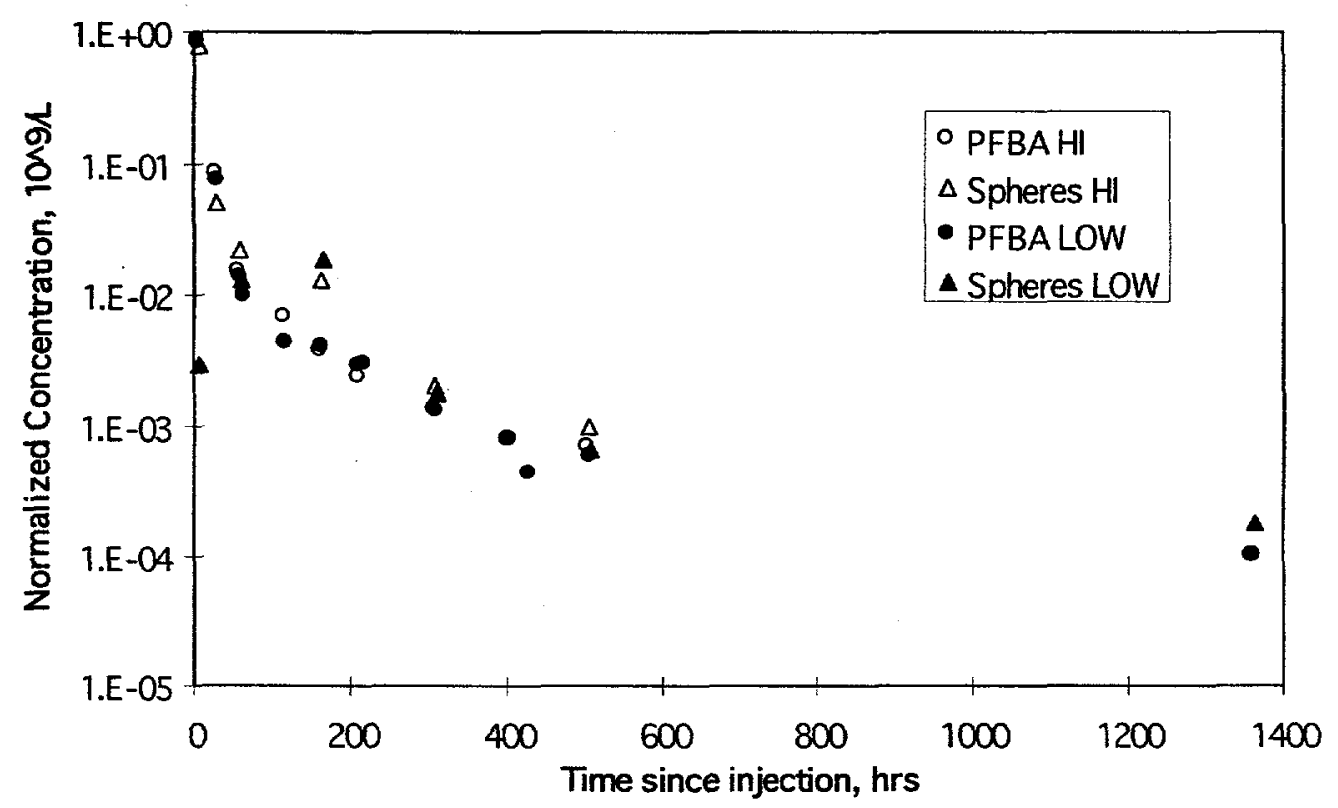

Figure 9. Tracer concentrations (normalized to injection concentration) in discrete bailer samples from well \#2. "HI" refers to upper part of injection interval, and "LOW" refers to lower part of interval. Solute data courtesy of IT Corporation.

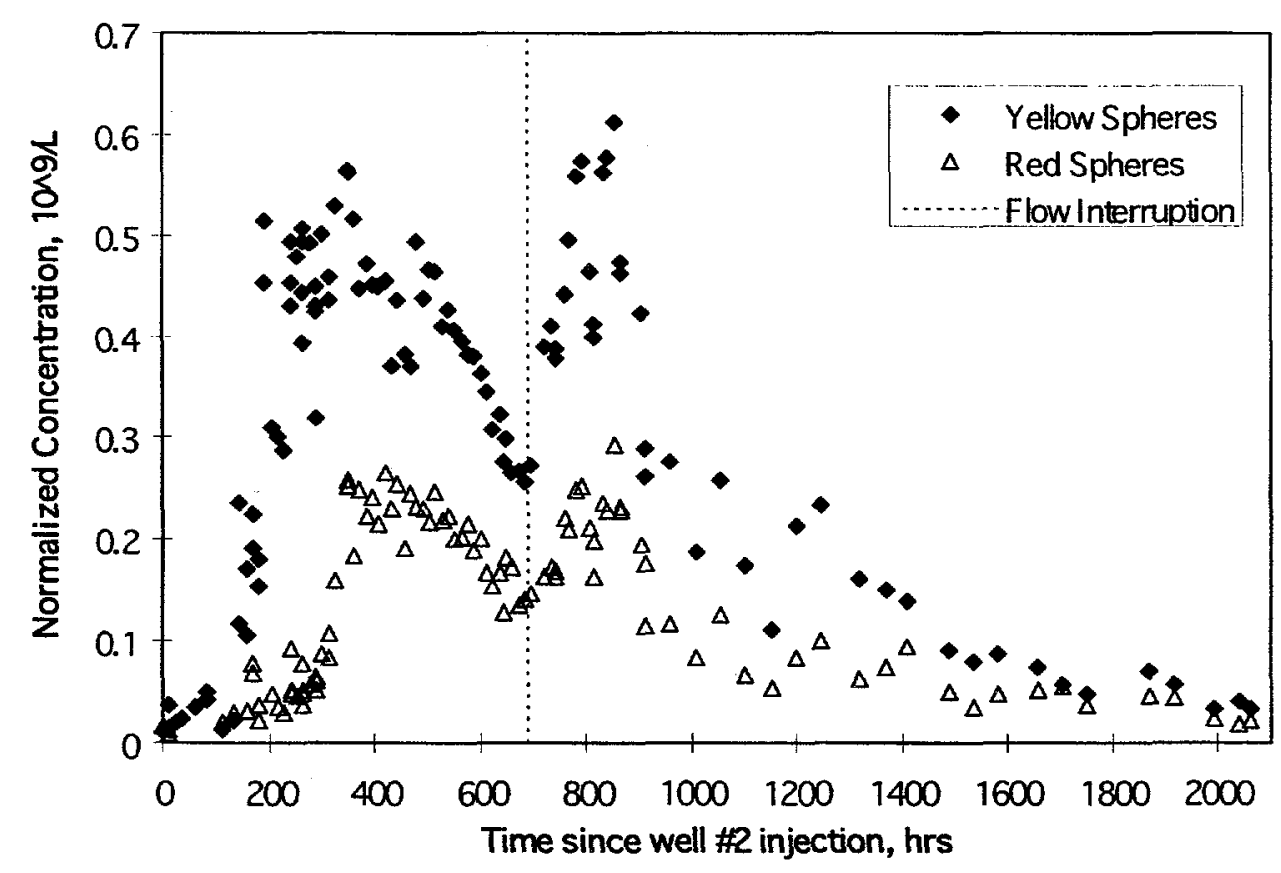

Figure 10. Microsphere responses as a function of time since injection into well \#2. Dashed line shows approximate time of flow interruption. 


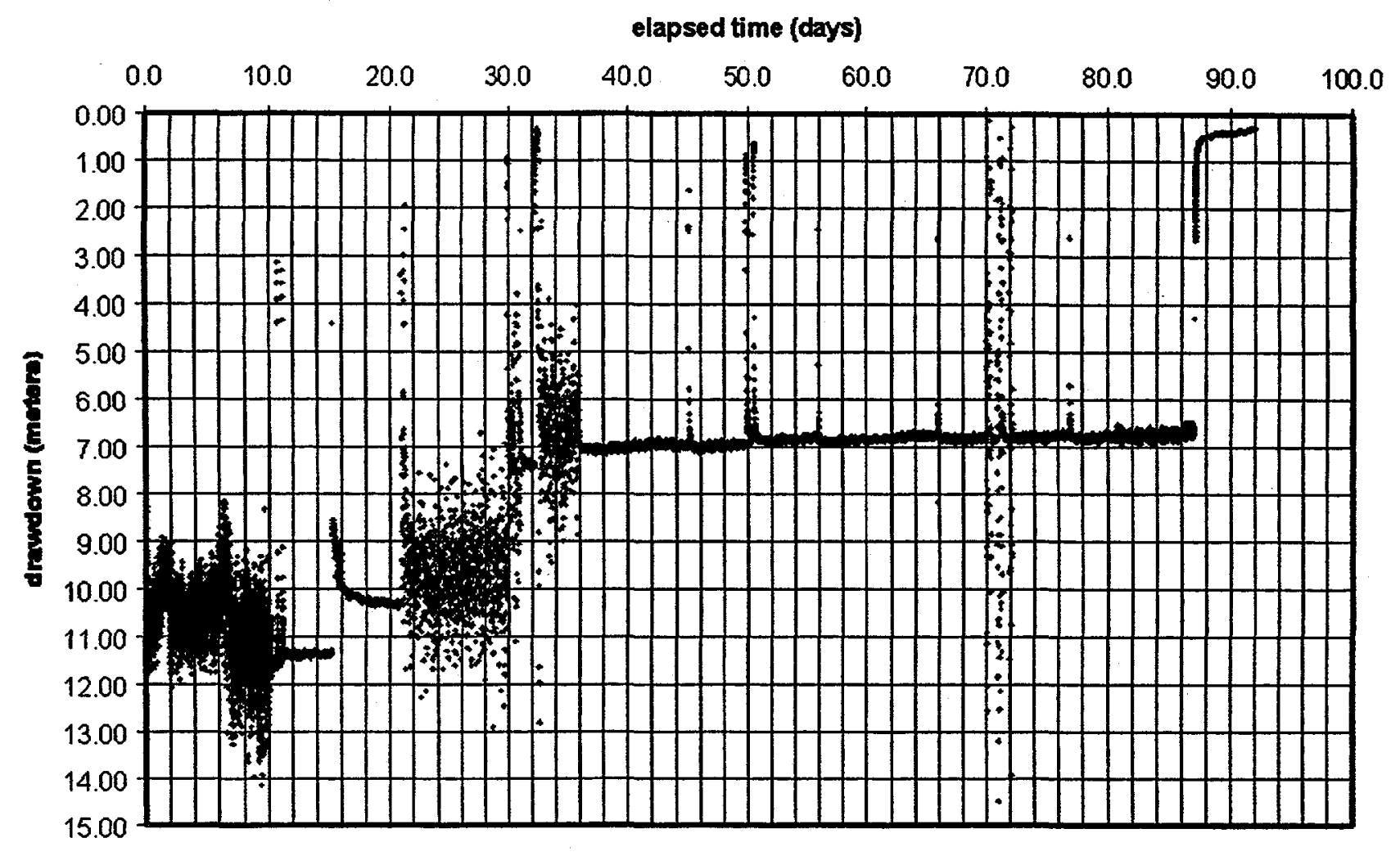

Figure 11. Flow rate (upper curve) and pressure drawdown (lower curve) history in well \#3 (taken from IT, 1998). Flow interruption and subsequent discontinuity in drawdown after flow was restarted (at about 30 days) coincided with the beginning of the second peak of both microspheres (see Figure 10). 
Physical System

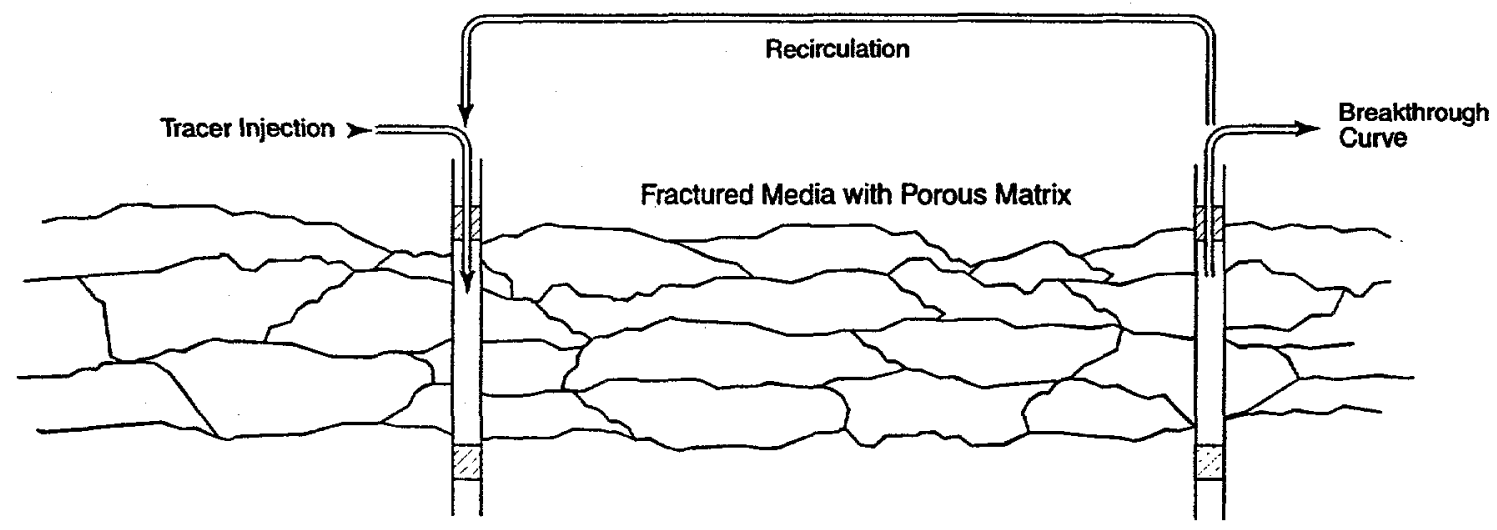

Conceptual Model

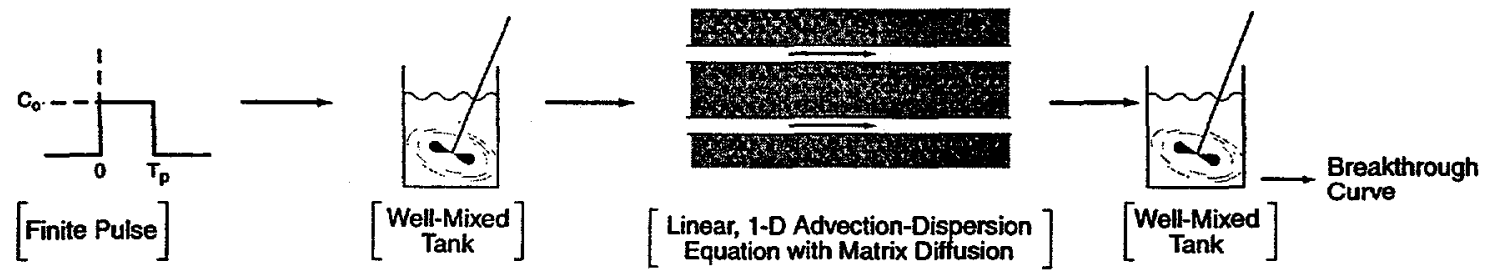

Laplace Transform Transfer Functions

\begin{tabular}{|c|c|c|c|}
\hline$C_{0}\left(\frac{1-e^{-T_{p} s}}{s}\right)$ & $\frac{a_{1}}{s+a_{1}}$ & $\exp \left[\frac{P e}{2}\left(1-\sqrt{1+\frac{4 \tau R_{f} s}{P e}}\left(1+\frac{\phi}{b R_{i}} \sqrt{\frac{R_{m} D_{m}}{s}}\right)\right)\right]$ & $\frac{a_{2}}{s+a_{2}}$ \\
\hline $\begin{array}{l}C_{o}=\text { injection concentration } \\
T_{p}=\text { duration of pulse, sec }\end{array}$ & $a_{1}=$ decay time ${ }^{-1}, \sec ^{-1}$ & $\begin{array}{l}\phi=\text { matrix porosity } \\
b=\text { fracture half aperture, } \mathrm{cm} \\
\mathrm{R}_{\mathrm{f}}=\text { fracture retardation factor } \\
\mathrm{R}_{\mathrm{m}}=\text { matrix retardation factor } \\
D_{m}=\text { diffusion coefficient in matrix }, \mathrm{cm}^{2} / \mathrm{sec} \\
\tau=\text { mean fluid residence time, } \mathrm{sec} \\
\mathrm{Pe}=\text { Peclet number }=\frac{L}{\alpha} \text { (see text) }\end{array}$ & $a_{2}=$ decay time ${ }^{-1}, \sec ^{-1}$ \\
\hline
\end{tabular}

Figure 12. Physical system, conceptual model, and Laplace transform transfer functions used to interpret tracer tests. (Note: Recirculation feature not used in interpretations because there was no recirculation.) 


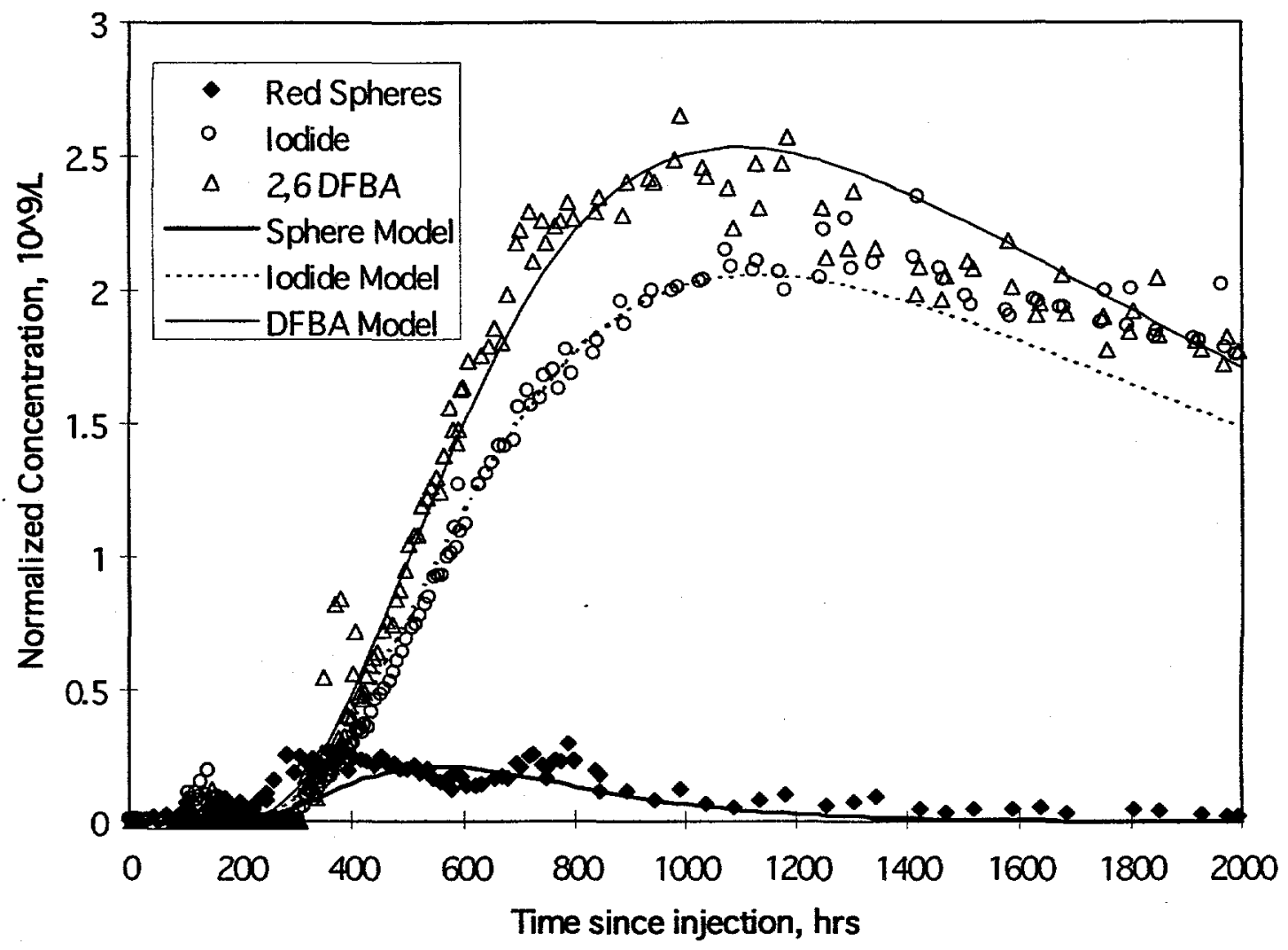

Figure 13. RELAP model fits to tracer responses between well \#1 and well \#3. Model parameters resulting in the best fits are given in Table 3. 


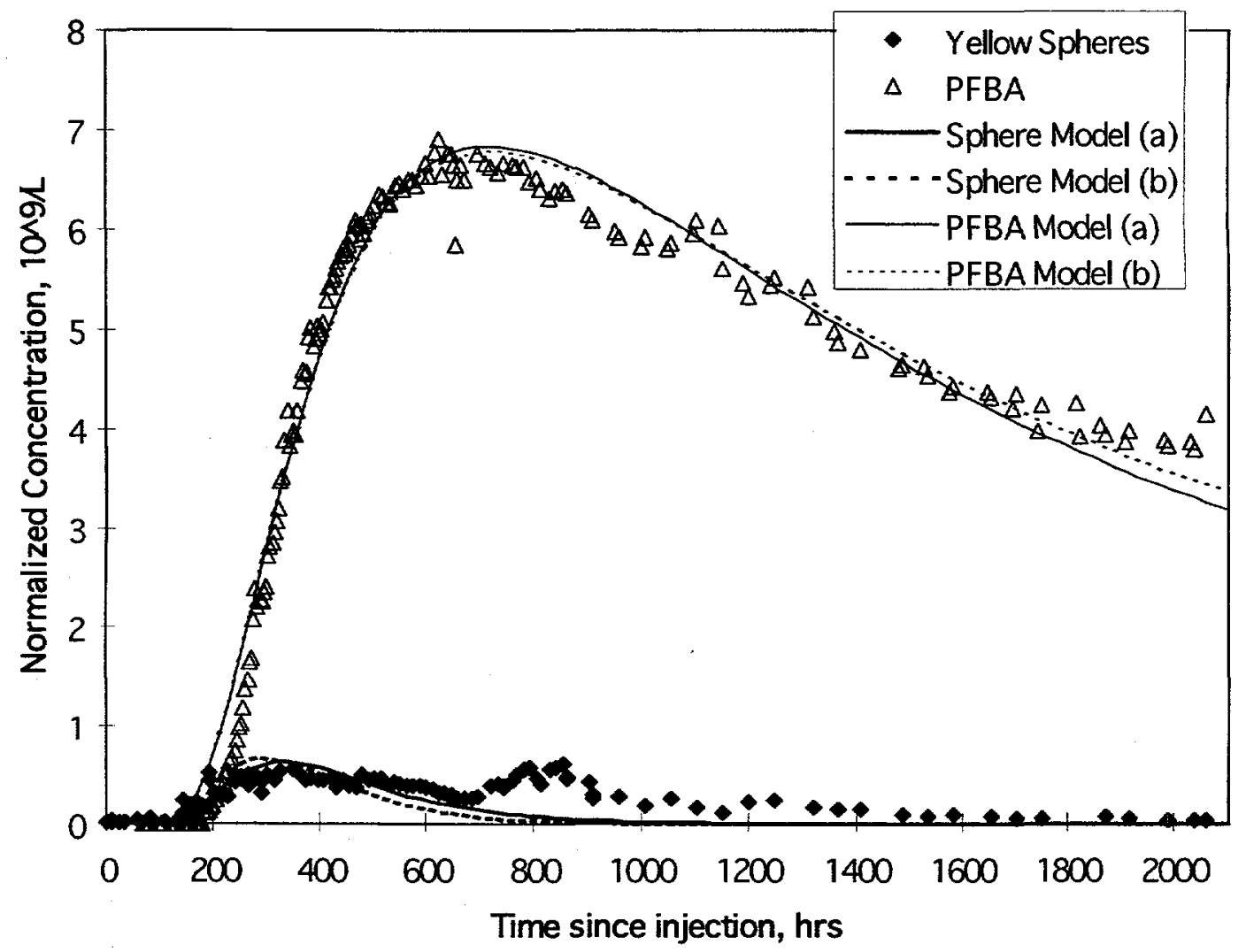

Figure 14. RELAP model fits to tracer responses between well \#2 and well \#3. "(a)" denotes fits assuming PFBA matrix diffusion coefficient is same as for 2,6-DFBA between wells $\# 1$ and \#3, and "(b)" denotes fits assuming PFBA matrix diffusion coefficient is same as for 2,6-DFBA between wells \#1 and \#2. The similarity of the two PFBA fits illustrates the nonuniqueness of fitting a single tracer data set with both matrix diffusion and dispersivity as adjustable parameters. Model parameters resulting in the best fits are given in Table 3. 


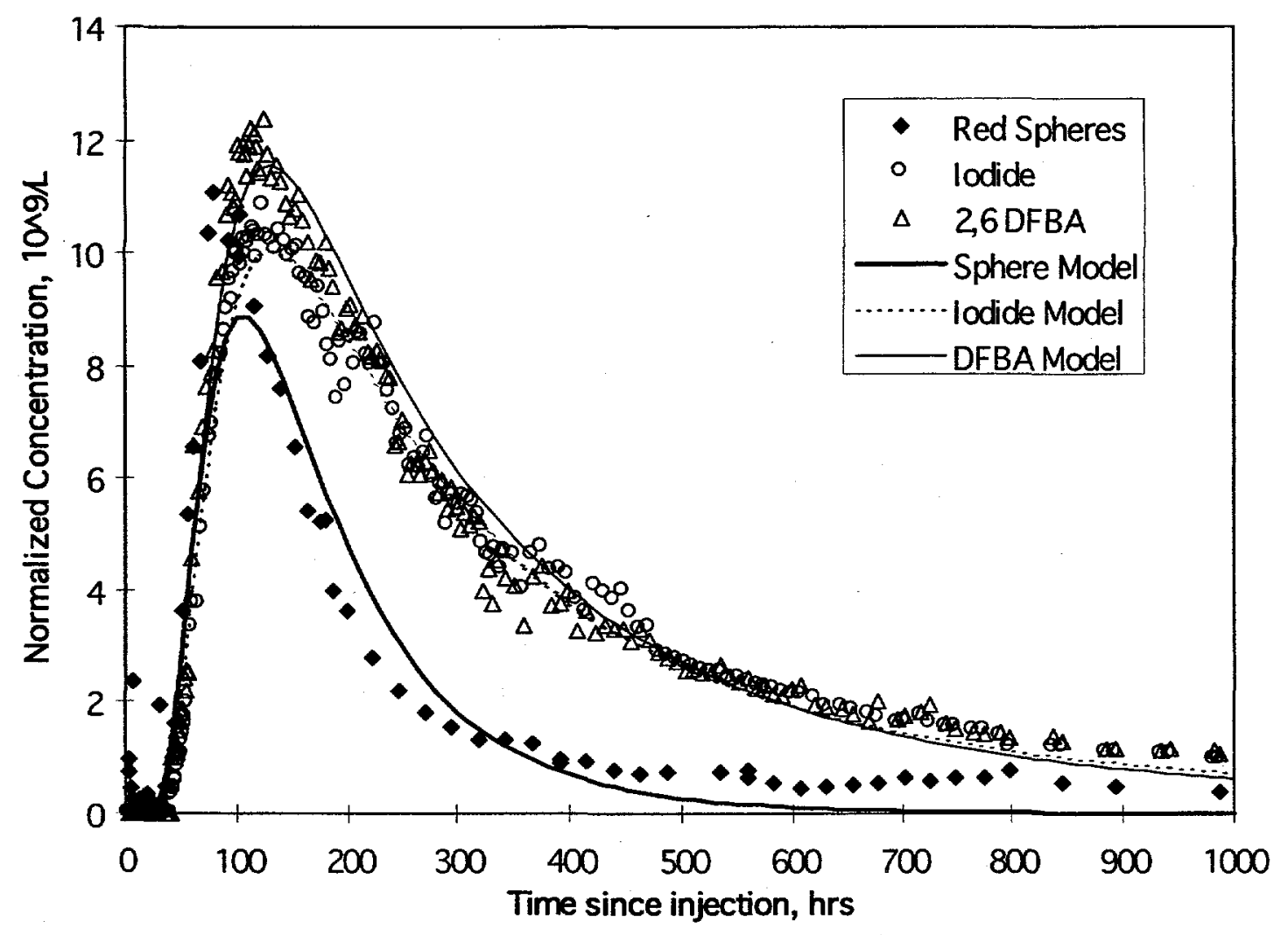

Figure 15. RELAP model fits to tracer responses between well \#1 and well \#2. Model parameters resulting in the best fits are given in Table 3. 


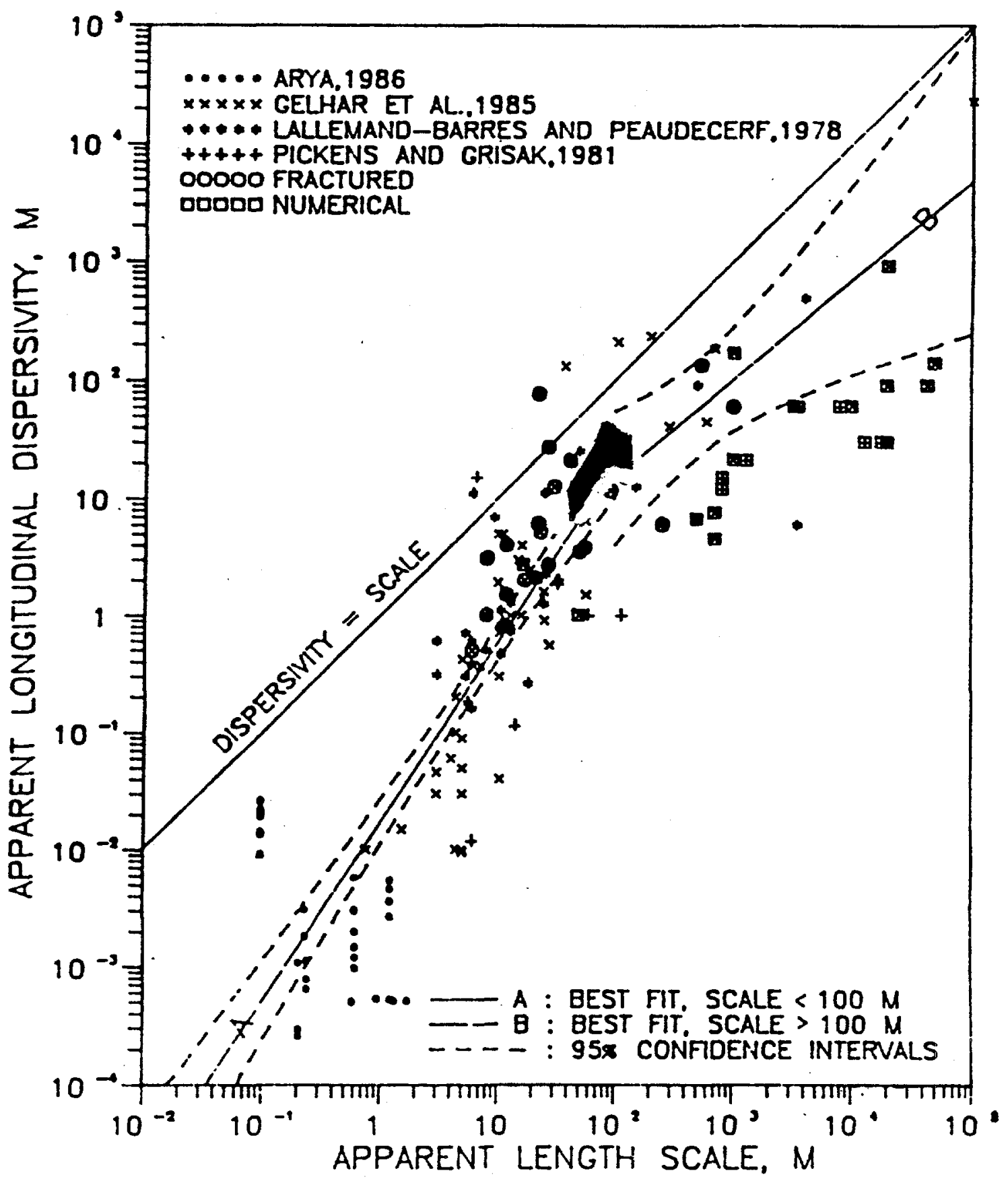

Figure 16. Plot of longitudinal dispersivity vs. length scale showing range of values derived from interpretations of the BULLION FGE tracer responses (blackened area). Plot taken from Neuman, S. P., Water Resources Research 26 (8), p. 1755, 1990, copyright 1990 by the American Geophysical Union. 


\section{Appendix A}

\section{Microsphere Data from the BULLION Forced-Gradient Experiment}

The tables in this appendix contain all of the microsphere data from the BULLION forced-gradient experiment. The tables list the date and time the samples were collected and the concentration of yellow and red spheres (number $/ \mathrm{ml}$ ) in each sample. The yellow spheres were injected into ER-20-6 \#2 at 17:20 on 6/3/97, with injection lasting until 22:45. The red spheres were injected into ER-20-6 \#1 at 11:07 on 6/6/97, with injection lasting until 16:15. Pumping of well \#2 was initiated on 6/6/97 at 11:17. Pumping of well \#1 was initiated on 6/8/97 at 11:15. All measurements were conducted by flow cytometry in accordance with approved UGTA standard operating procedure, LANL-CST-04, Rev. 0, "Use of a Flow Cytometer to Determine Particle Concentrations in Solution" (Reimus, 1997).

It should be noted that the times associated with the discrete bailer samples, as recorded in the subsequent tables in this appendix, do not always exactly match the times recorded on chain-of-custody sheets (although agreement is generally within a few hours). The discrepancies occur because some of the discrete samples were assigned the times that they were bottled, which was up to a few hours after the samples were actually collected downhole. The tables in this appendix are intended to match the actual sample collection times (when the bailer was opened, per Desert Research Institute field notebook) rather than the times on the chain-of-custody forms. These discrepancies did not occur for the pumped samples.

\section{Appendix A References}

Reimus, P. W., Use of a flow cytometer to determine particle concentrations in solution, Los Alamos National Laboratory standard operating procedure LANL-CST-04, Rev. 0, 1997. 
Table A-1. Well \#3 Data

\begin{tabular}{|c|c|c|c|c|}
\hline \multicolumn{2}{|c|}{ Pumped Samples: } & \multirow[b]{2}{*}{ Time of Day } & \multirow[b]{2}{*}{ Yellow, \#/ml } & \multirow[b]{2}{*}{ Red, \#/ml } \\
\hline Sample ID & Date & & & \\
\hline 3TRCR001 & $6 / 3 / 97$ & 18:01 & 19 & 27 \\
\hline 3TRCR023 & $6 / 4 / 97$ & $5: 00$ & 62 & 14 \\
\hline 3TRCR023 & $6 / 4 / 97$ & $5: 00$ & 24 & 19 \\
\hline 3TRCR047 & $6 / 4 / 97$ & $17: 00$ & 35 & $75^{\star}$ \\
\hline 3TRCR060 & $6 / 5 / 97$ & $5: 30$ & 40 & $113^{*}$ \\
\hline 3TRCR084 & $6 / 6 / 97$ & $5: 30$ & 58 & $126^{*}$ \\
\hline 3TRCR102 & $6 / 7 / 97$ & $5: 30$ & 72 & $114^{*}$ \\
\hline 3TRCR102 & $6 / 7 / 97$ & $5: 30$ & 85 & $89^{*}$ \\
\hline 3TRCR115 & $6 / 8 / 97$ & $7: 30$ & 22 & 31 \\
\hline 3TRCR123 & $6 / 9 / 97$ & $5: 29$ & 37 & 47 \\
\hline 3TRCR126 & $6 / 9 / 97$ & $17: 30$ & 197 & $300^{*}$ \\
\hline 3TRCR126 & $6 / 9 / 97$ & $17: 30$ & 395 & $449^{\star}$ \\
\hline 3TRCR130 & $6 / 10 / 97$ & $9: 30$ & 288 & $210^{*}$ \\
\hline 3TRCR130 & $6 / 10 / 97$ & $9: 30$ & 177 & 49 \\
\hline 3TRCR132 & $6 / 10 / 97$ & $17: 30$ & 321 & 107 \\
\hline 3TRCR132 & $6 / 10 / 97$ & $17: 30$ & 378 & 123 \\
\hline 3TRCR135 & $6 / 111 / 97$ & $5: 30$ & 302 & 57 \\
\hline 3TRCR135 & $6 / 11 / 97$ & $5: 30$ & 260 & 36 \\
\hline 3TRCR138 & $6 / 11 / 97$ & $17: 30$ & 760 & $179^{*}$ \\
\hline 3TRCR138 & $6 / 111 / 97$ & $17: 30$ & 864 & $271^{*}$ \\
\hline 3TRCR141 & $6 / 12 / 97$ & $5: 30$ & 520 & 75 \\
\hline 3TRCR144 & $6 / 12 / 97$ & $17: 30$ & 504 & 56 \\
\hline 3TRCR147 & $6 / 13 / 97$ & $5: 30$ & 482 & 46 \\
\hline 3TRCR150 & $6 / 13 / 97$ & $17: 30$ & 760 & 82 \\
\hline 3TRCR150 & $6 / 13 / 97$ & $17: 30$ & 829 & 146 \\
\hline 3TRCR150 & $6 / 13 / 97$ & $17: 30$ & 724 & 76 \\
\hline 3TRCR153 & $6 / 14 / 97$ & $5: 30$ & 805 & 74 \\
\hline 3TRCR156 & $6 / 14 / 97$ & $17: 30$ & 660 & 59 \\
\hline 3TRCR156 & $6 / 14 / 97$ & $17: 30$ & 853 & 122 \\
\hline 3TRCR156 & $6 / 14 / 97$ & $17: 30$ & 831 & 83 \\
\hline 3TRCR156 & $6 / 14 / 97$ & $17: 30$ & 745 & 76 \\
\hline 3TRCR159 & $6 / 15 / 97$ & $5: 30$ & 826 & 89 \\
\hline 3TRCR162 & $6 / 15 / 97$ & $17: 30$ & 714 & 96 \\
\hline 3TRCR162 & $6 / 15 / 97$ & $17: 30$ & 538 & 97 \\
\hline 3TRCR162 & $6 / 15 / 97$ & $17: 30$ & 723 & 81 \\
\hline 3TRCR162 & $6 / 15 / 97$ & $17: 30$ & 755 & 102 \\
\hline 3TRCR165 & $6 / 16 / 97$ & $5: 30$ & 842 & 136 \\
\hline 3TRCR168 & $6 / 16 / 97$ & $17: 30$ & 772 & 130 \\
\hline 3TRCR168 & $6 / 16 / 97$ & $17: 30$ & 732 & 170 \\
\hline 3TRCR171 & $6 / 17 / 97$ & $5: 30$ & 889 & 250 \\
\hline 3TRCR174 & $6 / 17 / 97$ & $17: 30$ & $1380^{*}$ & $1006^{*}$ \\
\hline 3TRCR177 & $6 / 18 / 97$ & $5: 30$ & 944 & 406 \\
\hline 3TRCR177 & $6 / 18 / 97$ & $5: 30$ & 948 & 395 \\
\hline 3TRCR180 & $6 / 18 / 97$ & $17: 30$ & 868 & 288 \\
\hline 3TRCR183 & $6 / 19 / 97$ & $5: 30$ & 751 & 392 \\
\hline 3TRCR186 & $6 / 19 / 97$ & $17: 30$ & 793 & 350 \\
\hline 3TRCR189 & $6 / 20 / 97$ & $5: 30$ & 759 & 379 \\
\hline 3TRCR192 & $6 / 20 / 97$ & $17: 30$ & 754 & 339 \\
\hline
\end{tabular}


Table A-1. Well \#3 Data

\begin{tabular}{|c|c|c|c|c|}
\hline Sample ID & Date & Time of Day & Yellow, \#/ml & Red, \#/ml \\
\hline 3TRCR195 & $6 / 21 / 97$ & $5: 30$ & 764 & 418 \\
\hline 3TRCR198 & $6 / 21 / 97$ & $17: 30$ & 624 & 361 \\
\hline 3TRCR201 & $6 / 22 / 97$ & $5: 30$ & 733 & 399 \\
\hline 3TRCR204 & $6 / 22 / 97$ & $17: 30$ & 643 & 299 \\
\hline 3TRCR207 & $6 / 23 / 97$ & $5: 30$ & 624 & 385 \\
\hline 3TRCR210 & $6 / 23 / 97$ & $17: 30$ & $1060^{*}$ & $498^{*}$ \\
\hline 3TRCR210 & $6 / 23 / 97$ & $17: 30$ & $1177^{*}$ & $538^{\star}$ \\
\hline 3TRCR210 & $6 / 23 / 97$ & $17: 30$ & 829 & 365 \\
\hline 3TRCR213 & $6 / 24 / 97$ & $5: 30$ & 735 & 361 \\
\hline 3TRCR216 & $6 / 24 / 97$ & $17: 30$ & 782 & 340 \\
\hline 3TRCR219 & $6 / 25 / 97$ & $5: 30$ & 780 & 389 \\
\hline 3TRCR222 & $6 / 25 / 97$ & $17: 30$ & 688 & 343 \\
\hline 3TRCR225 & $6 / 26 / 97$ & $5: 30$ & 716 & 350 \\
\hline 3TRCR228 & $6 / 26 / 97$ & $17: 30$ & 682 & 314 \\
\hline 3TRCR231 & $6 / 27 / 97$ & $5: 33$ & 665 & 318 \\
\hline 3TRCR234 & $6 / 27 / 97$ & $17: 30$ & 644 & 339 \\
\hline 3TRCR237 & $6 / 28 / 97$ & $5: 30$ & 639 & 296 \\
\hline 3TRCR240 & $6 / 28 / 97$ & $17: 30$ & 612 & 315 \\
\hline 3TRCR243 & $6 / 29 / 97$ & $5: 30$ & 579 & 261 \\
\hline 3TRCR246 & $6 / 29 / 97$ & $17: 30$ & 517 & 241 \\
\hline 3TRCR249 & $6 / 30 / 97$ & $5: 30$ & 543 & 263 \\
\hline 3TRCR251 & $6 / 30 / 97$ & $13: 30$ & 465 & 200 \\
\hline 3TRCR252 & $6 / 30 / 97$ & $17: 30$ & 501 & 286 \\
\hline 3TRCR255 & $7 / 1 / 97$ & $5: 30$ & 446 & 272 \\
\hline 3TRCR258 & $7 / 1 / 97$ & $17: 15$ & 450 & 212 \\
\hline 3TRCR259 & $7 / 2 / 97$ & $7: 30$ & 432 & 221 \\
\hline 3TRCR260 & $7 / 2 / 97$ & $17: 00$ & 458 & 231 \\
\hline 3TRCR262 & $7 / 3 / 97$ & $17: 00$ & 654 & 256 \\
\hline 3TRCR263 & $7 / 4 / 97$ & $8: 00$ & 688 & 271 \\
\hline 3TRCR264 & $7 / 4 / 97$ & $16: 30$ & 635 & 265 \\
\hline 3TRCR264 & $7 / 4 / 97$ & $16: 30$ & 651 & 257 \\
\hline 3TRCR265 & $7 / 5 / 97$ & $11: 00$ & 741 & 348 \\
\hline 3TRCR266 & $7 / 5 / 97$ & 17:00 & 832 & 329 \\
\hline 3TRCR267 & $7 / 6 / 97$ & $8: 04$ & 939 & 392 \\
\hline 3TRCR268 & $7 / 6 / 97$ & $17: 00$ & 965 & 397 \\
\hline 3TRCR269 & $7 / 7 / 97$ & $8: 00$ & 781 & 332 \\
\hline 3TRCR270 & $7 / 7 / 97$ & $16: 00$ & 692 & 257 \\
\hline 3TRCR270 & $7 / 7 / 97$ & $16: 00$ & 670 & 313 \\
\hline 3TRCR271 & $7 / 8 / 97$ & $8: 30$ & 946 & 370 \\
\hline 3TRCR272 & $7 / 8 / 97$ & $17: 00$ & 970 & 359 \\
\hline 3TRCR273 & $7 / 9 / 97$ & $8: 00$ & 1030 & 462 \\
\hline 3TRCR274 & $7 / 9 / 97$ & $17: 00$ & 778 & 358 \\
\hline 3TRCR274 & $7 / 9 / 97$ & $17: 00$ & 796 & 364 \\
\hline 3TRCR275 & $7 / 11 / 97$ & $8: 00$ & 712 & 305 \\
\hline 3TRCR276 & $7 / 11 / 97$ & $16: 30$ & 441 & 182 \\
\hline 3TRCR276 & $7 / 11 / 97$ & $16: 30$ & 487 & 278 \\
\hline 3TRCR278 & $7 / 13 / 97$ & $16: 30$ & 465 & 183 \\
\hline 3TRCR280 & $7 / 15 / 97$ & $17: 00$ & 314 & 132 \\
\hline 3TRCR282 & $7 / 17 / 97$ & $16: 30$ & 433 & 198 \\
\hline
\end{tabular}




\begin{tabular}{|c|c|c|c|c|}
\hline Sample ID & Date & Time of Day & Yellow, \#/ml & Red, \#/ml \\
\hline 3TRCR284 & $7 / 19 / 97$ & $16: 30$ & 292 & 105 \\
\hline 3TRCR286 & $7 / 21 / 97$ & 16:30 & 187 & 85 \\
\hline 3TRCR288 & $7 / 23 / 97$ & 16:30 & 359 & 132 \\
\hline 3TRCR290 & $7 / 25 / 97$ & $16: 10$ & 394 & 158 \\
\hline 3TRCR292 & $7 / 28 / 97$ & $16: 30$ & 270 & 99 \\
\hline 3TRCR294 & $7 / 30 / 97$ & $16: 30$ & 252 & 118 \\
\hline 3TRCR295 & $8 / 1 / 97$ & $8: 30$ & 234 & 150 \\
\hline 3TRCR297 & $8 / 4 / 97$ & 17:00 & 154 & 78 \\
\hline 3TRCR299 & $8 / 6 / 97$ & $16: 30$ & 134 & 56 \\
\hline 3TRCR301 & $8 / 8 / 97$ & $16: 00$ & 146 & 75 \\
\hline 3TRCR303 & $8 / 11 / 97$ & $16: 30$ & 126 & 81 \\
\hline 3TRCR305 & $8 / 13 / 97$ & $15: 30$ & 98 & 86 \\
\hline 3TRCR307 & $8 / 15 / 97$ & $15: 30$ & 82 & 58 \\
\hline 3TRCR309 & $8 / 18 / 97$ & $16: 30$ & $314^{*}$ & $472^{*}$ \\
\hline 3TRCR311 & $8 / 20 / 97$ & $16: 30$ & 119 & 72 \\
\hline 3TRCR313 & $8 / 22 / 97$ & $15: 00$ & 98 & 69 \\
\hline 3TRCR315 & $8 / 25 / 97$ & $16: 30$ & 57 & 38 \\
\hline 3TRCR317 & $8 / 27 / 97$ & $16: 30$ & 69 & 30 \\
\hline 3TRCR318 & $8 / 28 / 97$ & $13: 00$ & 55 & 36 \\
\hline & & & & \\
\hline
\end{tabular}




\begin{tabular}{|c|c|c|c|c|}
\hline \multicolumn{2}{|c|}{ Pumpback Samples: } & & & \\
\hline Sample ID & Date & Time of Day & Yellow, \#/ml & Red, \#/ml \\
\hline 2TRCR000 & $6 / 6 / 97$ & $13: 45$ & 1676417 & $7431^{*}$ \\
\hline 2TRCR000 & $6 / 6 / 97$ & $13: 45$ & 1830035 & $1166^{*}$ \\
\hline 2TRCR003 & $6 / 6 / 97$ & $14: 30$ & 1664290 & $1519^{*}$ \\
\hline 2TRCR007 & $6 / 6 / 97$ & $15: 30$ & 1460629 & $721^{*}$ \\
\hline 2TRCR019 & $6 / 6 / 97$ & $18: 30$ & 1104128 & $3732^{*}$ \\
\hline 2TRCR019 & $6 / 6 / 97$ & $18: 30$ & 1240108 & 383 \\
\hline 2TRCR043 & $6 / 7 / 97$ & $0: 32$ & 896290 & 400 \\
\hline 2TRCR057 & $6 / 7 / 97$ & 6:07 & 695101 & 559 \\
\hline 2TRCR065 & $6 / 7 / 97$ & $10: 15$ & 719686 & 381 \\
\hline 2TRCR077 & $6 / 7 / 97$ & $18: 45$ & 555958 & $3085^{\star}$ \\
\hline 2TRCR077 & $6 / 7 / 97$ & $18: 45$ & 736228 & 306 \\
\hline 2TRCR081 & $6 / 7 / 97$ & $22: 45$ & 505902 & 744 \\
\hline 2TRCR089 & $6 / 8 / 97$ & $6: 45$ & 481998 & 2540 \\
\hline 2TRCR097 & $6 / 8 / 97$ & $14: 48$ & 418000 & 5710 \\
\hline 2TRCR101 & $6 / 8 / 97$ & $18: 45$ & 407218 & 8436 \\
\hline 2TRCR107 & $6 / 9 / 97$ & $0: 45$ & 357430 & 10324 \\
\hline 2TRCR113 & $6 / 9 / 97$ & $6: 40$ & 372180 & 12684 \\
\hline 2TRCR120 & $6 / 9 / 97$ & $13: 45$ & 355356 & 16277 \\
\hline 2TRCR122 & $6 / 9 / 97$ & $17: 45$ & 346611 & 17409 \\
\hline 2TRCR129 & $6 / 10 / 97$ & $7: 45$ & 282289 & 16042 \\
\hline 2TRCR134 & $6 / 10 / 97$ & $17: 45$ & 227302 & 16762 \\
\hline 2TRCR134 & $6 / 10 / 97$ & $17: 45$ & 260658 & 15609 \\
\hline 2TRCR140 & $6 / 11 / 97$ & $5: 45$ & 230746 & 14245 \\
\hline 2TRCR145 & $6 / 11 / 97$ & $17: 45$ & 212331 & 12859 \\
\hline 2TRCR148 & $6 / 12 / 97$ & $5: 46$ & 200091 & 11946 \\
\hline 2TRCR151 & $6 / 12 / 97$ & $17: 45$ & 178905 & 10290 \\
\hline 2TRCR154 & $6 / 13 / 97$ & $6: 00$ & 159366 & 8541 \\
\hline 2TRCR157 & $6 / 13 / 97$ & $17: 45$ & 153332 & 8218 \\
\hline 2TRCR158 & $6 / 13 / 97$ & $21: 45$ & 155156 & 8276 \\
\hline 2TRCR160 & $6 / 14 / 97$ & $5: 45$ & 142181 & 6285 \\
\hline 2TRCR163 & $6 / 14 / 97$ & $17: 45$ & 126796 & 5737 \\
\hline 2TRCR169 & $6 / 15 / 97$ & $17: 45$ & 111363 & 4403 \\
\hline 2TRCR178 & $6 / 16 / 97$ & $17: 45$ & 99934 & 3454 \\
\hline 2TRCR181 & $6 / 17 / 97$ & $17: 45$ & 92017 & 2833 \\
\hline 2TRCR187 & $6 / 18 / 97$ & $17: 45$ & 81502 & 2438 \\
\hline 2TRCR193 & $6 / 19 / 97$ & $17: 45$ & 74597 & 2089 \\
\hline 2TRCR199 & $6 / 20 / 97$ & $17: 45$ & 86639 & 2067 \\
\hline 2TRCR202 & $6 / 21 / 97$ & $17: 30$ & 71579 & 1993 \\
\hline 2TRCR205 & $6 / 22 / 97$ & $17: 45$ & 56087 & 1447 \\
\hline 2TRCR205 & $6 / 22 / 97$ & $17: 45$ & 54898 & 1553 \\
\hline 2TRCR208 & $6 / 23 / 97$ & $17: 45$ & 53592 & 1473 \\
\hline 2TRCR211 & $6 / 24 / 97$ & $17: 45$ & 48222 & 1237 \\
\hline 2TRCR214 & $6 / 25 / 97$ & $17: 45$ & 46609 & 1140 \\
\hline 2TRCR217 & $6 / 26 / 97$ & $17: 45$ & 40731 & 1148 \\
\hline 2TRCR223 & $6 / 28 / 97$ & $17: 45$ & 37613 & 1188 \\
\hline 2TRCR226 & $6 / 29 / 97$ & $17: 45$ & 34855 & 1024 \\
\hline 2TRCR226 & $6 / 29 / 97$ & $17: 45$ & 33673 & 1202 \\
\hline 2TRCR229 & $6 / 30 / 97$ & $17: 45$ & 38892 & 861 \\
\hline
\end{tabular}


Table A-2. Well \#2 Data

\begin{tabular}{|c|c|c|c|c|}
\hline Sample ID & Date & Time of Day & Yellow, \#/ml & Red, \#/ml \\
\hline 2TRCR232 & $7 / 1 / 97$ & $17: 15$ & 38220 & 729 \\
\hline 2TRCR234 & $7 / 2 / 97$ & 17:00 & 33199 & 757 \\
\hline 2TRCR236 & $7 / 3 / 97$ & $17: 00$ & 27428 & 839 \\
\hline 2TRCR238 & $7 / 4 / 97$ & $16: 30$ & 26588 & 855 \\
\hline 2TRCR241 & $7 / 5 / 97$ & $17: 01$ & 31328 & 1000 \\
\hline 2TRCR243 & $7 / 6 / 97$ & $17: 00$ & 27163 & 941 \\
\hline 2TRCR245 & $7 / 7 / 97$ & $16: 00$ & 25622 & 998 \\
\hline 2TRCR247 & $7 / 8 / 97$ & $17: 00$ & 23755 & 1014 \\
\hline 2TRCR249 & $7 / 9 / 97$ & $17: 00$ & 22417 & 1232 \\
\hline 2TRCR251 & $7 / 11 / 97$ & $16: 30$ & 19665 & 857 \\
\hline 2TRCR253 & $7 / 13 / 97$ & $16: 30$ & 17493 & 762 \\
\hline 2TRCR257 & $7 / 17 / 97$ & 13:15 & 14493 & 620 \\
\hline 2TRCR257 & $7 / 17 / 97$ & $13: 15$ & 14866 & 608 \\
\hline 2TRCR258 & $7 / 28 / 97$ & $16: 30$ & 18000 & 452 \\
\hline 2TRCR258 & $7 / 28 / 97$ & $16: 30$ & 21134 & 585 \\
\hline 2TRCR260 & $7 / 30 / 97$ & $16: 30$ & 12071 & 543 \\
\hline 2TRCR261 & $8 / 1 / 97$ & $8: 30$ & 12031 & 450 \\
\hline 2TRCR264 & $8 / 4 / 97$ & 17:00 & 8196 & 361 \\
\hline 2TRCR264 & $8 / 4 / 97$ & $17: 00$ & 8063 & 344 \\
\hline 2TRCR264 & $8 / 4 / 97$ & $17: 00$ & 8510 & 398 \\
\hline 2TRCR266 & $8 / 6 / 97$ & $16: 30$ & 7522 & 416 \\
\hline 2TRCR266 & $8 / 6 / 97$ & $16: 30$ & 7829 & 314 \\
\hline 2TRCR266 & $8 / 6 / 97$ & $16: 30$ & 7736 & 285 \\
\hline 2TRCR266 & $8 / 6 / 97$ & $16: 30$ & 7841 & 379 \\
\hline 2TRCR267 & $8 / 18 / 97$ & $16: 30$ & 9965 & 286 \\
\hline 2TRCR269 & $8 / 20 / 97$ & $16: 30$ & 6009 & 280 \\
\hline 2TRCR271 & $8 / 22 / 97$ & $15: 00$ & 5426 & 203 \\
\hline 2TRCR272 & $8 / 25 / 97$ & $9: 30$ & 6068 & 241 \\
\hline 2TRCR273 & $8 / 25 / 97$ & $16: 30$ & 5013 & 251 \\
\hline 2TRCR274 & $8 / 27 / 97$ & $9: 30$ & 4972 & 359 \\
\hline \multicolumn{5}{|c|}{ Discrete Bailer Samples: } \\
\hline Sample ID & Date & Time of Day & Yellow, \#/ml & Red, \#/ml \\
\hline 2LOWDSCRT01 & $6 / 4 / 97$ & $1: 25$ & $220159^{*}$ & 1250 \\
\hline 2LOWDSCRT03 & $6 / 6 / 97$ & $5: 30$ & 992822 & 232387 \\
\hline 2LOWDSCRTO6 & $6 / 10 / 97$ & 15:10 & 1409729 & 22005 \\
\hline 2LOWDSCRTO9 & $6 / 16 / 97$ & $15: 26$ & 134397 & 33373 \\
\hline 2LOWDSCRT12 & $6 / 24 / 97$ & $21: 15$ & 48834 & 3902 \\
\hline 2LOWDSCRT13 & $7 / 30 / 97$ & $12: 00$ & 13355 & 4981 \\
\hline 2UPDSCRT01 & $6 / 3 / 97$ & $23: 32$ & 58034100 & 79700 \\
\hline 2UPDSCRT02 & $6 / 4 / 97$ & 23:08 & 3824909 & 14886 \\
\hline 2UPDSCRT03 & $6 / 6 / 97$ & $3: 58$ & 1653525 & 6864 \\
\hline 2UPDSCRT05 & $6 / 10 / 97$ & $12: 25$ & 976204 & 44629 \\
\hline 2UPDSCRT07 & $6 / 16 / 97$ & $13: 17$ & 153094 & 36833 \\
\hline 2UPDSCRT09 & $6 / 24 / 97$ & $21: 15$ & 72661 & 15153 \\
\hline \multicolumn{5}{|c|}{ dered to be } \\
\hline
\end{tabular}


Table A-3. Well \#1 Data

\begin{tabular}{|c|c|c|c|c|}
\hline \multicolumn{2}{|c|}{ Pumpback Samples: } & \multirow[b]{2}{*}{ Time of Day } & \multirow[b]{2}{*}{ Yellow, \#/ml } & \multirow[b]{2}{*}{ Red, \#/ml } \\
\hline Sample ID & Date & & & \\
\hline 1TRCR003 & $6 / 8 / 97$ & $14: 15$ & Not Measured & 554355 \\
\hline 1TRCR050 & $6 / 9 / 97$ & $2: 15$ & Not Measured & 287920 \\
\hline 1TRCR070 & $6 / 9 / 97$ & $14: 45$ & Not Measured & 188405 \\
\hline 1TRCR086 & $6 / 10 / 97$ & $2: 45$ & Not Measured & 132311 \\
\hline 1TRCR096 & $6 / 10 / 97$ & $12: 45$ & 67 & 102307 \\
\hline 1TRCR109 & $6 / 11 / 97$ & $1: 45$ & 116 & 81828 \\
\hline 1TRCR121 & $6 / 11 / 97$ & $13: 45$ & 167 & 51052 \\
\hline 1TRCR127 & $6 / 12 / 97$ & $1: 45$ & 59 & 59071 \\
\hline 1TRCR133 & $6 / 12 / 97$ & $13: 45$ & 93 & 52511 \\
\hline 1TRCR139 & $6 / 13 / 97$ & $1: 45$ & 93 & 46582 \\
\hline 1TRCR145 & $6 / 13 / 97$ & $13: 45$ & 94 & 45481 \\
\hline 1TRCR148 & $6 / 14 / 97$ & $1: 45$ & 96 & 37907 \\
\hline 1TRCR151 & $6 / 14 / 97$ & $13: 45$ & 116 & 34736 \\
\hline 1TRCR154 & $6 / 15 / 97$ & $1: 45$ & 74 & 33882 \\
\hline 1TRCR157 & $6 / 15 / 97$ & $13: 45$ & 85 & 39787 \\
\hline 1TRCR160 & $6 / 16 / 97$ & $1: 45$ & 62 & 24311 \\
\hline 1TRCR163 & $6 / 16 / 97$ & $13: 45$ & 115 & 22613 \\
\hline 1TRCR166 & $6 / 17 / 97$ & $1: 45$ & 61 & 19122 \\
\hline 1TRCR169 & $6 / 17 / 97$ & 13:45 & 89 & 19883 \\
\hline 1TRCR172 & $6 / 18 / 97$ & $1: 45$ & 48 & 18932 \\
\hline 1TRCR172 & $6 / 18 / 97$ & $1: 45$ & 77 & 19775 \\
\hline 1TRCR175 & $6 / 18 / 97$ & $13: 45$ & 38 & 17783 \\
\hline 1TRCR178 & $6 / 19 / 97$ & $1: 45$ & 72 & 15739 \\
\hline 1TRCR181 & $6 / 19 / 97$ & $13: 45$ & 45 & 15073 \\
\hline 1TRCR184 & $6 / 20 / 97$ & $1: 45$ & 82 & 14202 \\
\hline 1TRCR187 & $6 / 20 / 97$ & $13: 45$ & 424 & 11480 \\
\hline 1TRCR187 & $6 / 20 / 97$ & $13: 45$ & 42 & 11795 \\
\hline 1TRCR189 & $6 / 21 / 97$ & $1: 45$ & 41 & 12940 \\
\hline 1TRCR189 & $6 / 21 / 97$ & 1:45 & 55 & 13085 \\
\hline 1TRCR192 & $6 / 22 / 97$ & $1: 45$ & 91 & 10881 \\
\hline 1TRCR195 & $6 / 23 / 97$ & $1: 45$ & 78 & 10842 \\
\hline 1TRCR198 & $6 / 24 / 97$ & $14: 52$ & 153 & 9702 \\
\hline 1TRCR201 & $6 / 25 / 97$ & $1: 45$ & 72 & 9093 \\
\hline 1TRCR204 & $6 / 26 / 97$ & $1: 45$ & 82 & 7951 \\
\hline 1TRCR204 & $6 / 26 / 97$ & $1: 45$ & 62 & 8020 \\
\hline 1TRCR204 & $6 / 26 / 97$ & $1: 45$ & 96 & 8076 \\
\hline 1TRCR207 & $6 / 27 / 97$ & $1: 45$ & 64 & 6723 \\
\hline 1TRCR207 & $6 / 27 / 97$ & $1: 45$ & 73 & 7083 \\
\hline 1TRCR210 & $6 / 28 / 97$ & $1: 45$ & 53 & 7320 \\
\hline 1TRCR210 & $6 / 28 / 97$ & $1: 45$ & 79 & 7118 \\
\hline 1TRCR213 & $6 / 29 / 97$ & 1:45 & 103 & 6929 \\
\hline 1TRCR215 & $6 / 29 / 97$ & $17: 45$ & 86 & 6488 \\
\hline 1TRCR216 & $6 / 30 / 97$ & $1: 45$ & 106 & 6951 \\
\hline 1TRCR216 & $6 / 30 / 97$ & $1: 45$ & 88 & 6968 \\
\hline 1TRCR218 & $6 / 30 / 97$ & $17: 45$ & 120 & 6733 \\
\hline 1TRCR218 & $6 / 30 / 97$ & $17: 45$ & 69 & 6433 \\
\hline 1TRCR219 & $7 / 1 / 97$ & $1: 45$ & 84 & 6819 \\
\hline 1TRCR221 & $7 / 1 / 97$ & $17: 15$ & 51 & 6209 \\
\hline
\end{tabular}


Table A-3. Well \#1 Data

\begin{tabular}{|c|c|c|c|c|}
\hline Sample ID & Date & Time of Day & Yellow, \#/ml & Red, \#/ml \\
\hline 1TRCR223 & $7 / 2 / 97$ & 17:00 & 65 & 4895 \\
\hline 1TRCR225 & $7 / 3 / 97$ & 17:00 & 36 & 4500 \\
\hline 1TRCR227 & $7 / 4 / 97$ & $16: 33$ & 35 & 4200 \\
\hline 1TRCR229 & $7 / 5 / 97$ & 17:00 & 29 & 4571 \\
\hline 1TRCR231 & $7 / 6 / 97$ & $17: 00$ & 56 & 4319 \\
\hline 1TRCR233 & $7 / 7 / 97$ & 16:00 & 39 & 3819 \\
\hline 1TRCR235 & $7 / 8 / 97$ & $17: 00$ & 29 & 3627 \\
\hline 1TRCR237 & $7 / 9 / 97$ & 17:00 & 21 & 3528 \\
\hline 1TRCR238 & $7 / 17 / 97$ & $8: 30$ & 36 & 4452 \\
\hline 1TRCR239 & $7 / 17 / 97$ & 13:20 & 34 & 3447 \\
\hline 1TRCR240 & $7 / 28 / 97$ & $16: 30$ & 24 & 3591 \\
\hline 1TRCR242 & $7 / 30 / 97$ & $16: 30$ & 22 & 2467 \\
\hline 1TRCR243 & $8 / 1 / 97$ & $8: 30$ & 54 & 2084 \\
\hline 1TRCR245 & $8 / 4 / 97$ & $17: 00$ & 20 & 1899 \\
\hline 1TRCR247 & $8 / 6 / 97$ & $16: 30$ & 38 & 1801 \\
\hline 1TRCR248 & $8 / 18 / 97$ & $16: 30$ & 70 & 2592 \\
\hline 1TRCR248 & $8 / 18 / 97$ & $16: 30$ & 44 & 2632 \\
\hline 1TRCR250 & $8 / 20 / 97$ & $16: 30$ & 92 & 1781 \\
\hline 1TRCR252 & $8 / 22 / 97$ & 15:00 & 50 & 1384 \\
\hline 1TRCR254 & $8 / 25 / 97$ & 16:30 & 23 & 1358 \\
\hline 1TRCR256 & $8 / 27 / 97$ & 15:00 & 26 & 1365 \\
\hline \multicolumn{5}{|c|}{ Discrete Bailer Samples: } \\
\hline Sample ID & Date & Time of Day & Yellow, \#/ml & Red, \#/ml \\
\hline 1LOWDSCRT01 & $6 / 6 / 97$ & $20: 45$ & 37248 & 22141478 \\
\hline 1LOWDSCRTO2 & $6 / 7 / 97$ & $20: 15$ & 10217 & 2322240 \\
\hline 1LOWDSCRT03 & $6 / 9 / 97$ & 18:00 & Not Measured & 924380 \\
\hline 1LOWDSCRT04 & $6 / 10 / 97$ & 19:15 & 662 & 126757 \\
\hline 1LOWDSCRT06 & $6 / 16 / 97$ & 19:30 & 923 & 28276 \\
\hline 1LOWDSCRT08 & $6 / 24 / 97$ & 16:15 & 311 & 10682 \\
\hline 1LOWDSCRTO9 & $7 / 30 / 97$ & 15:30 & 253 & 5441 \\
\hline 1UPDSCRT01 & $6 / 6 / 97$ & 18:22 & 26418 & 22030231 \\
\hline 1UPDSCRT02 & $6 / 7 / 97$ & 18:28 & 6358 & 2635342 \\
\hline 1UPDSCRT03 & $6 / 8 / 97$ & 18:00 & 48894 & 367270 \\
\hline 1UPDSCRT04 & $6 / 10 / 97$ & $17: 50$ & 1910 & 608015 \\
\hline 1UPDSCRT06 & $6 / 16 / 97$ & $17: 50$ & 2937 & 95193 \\
\hline 1UPDSCRT08 & $6 / 24 / 97$ & 14:35 & 5364 & 53345 \\
\hline 1UPDSCRT09 & $7 / 30 / 97$ & $13: 45$ & 1075 & 18884 \\
\hline
\end{tabular}




\section{Appendix B}

\section{Description of Mathematical Models in the RELAP Computer Code}

To model tracer transport in a dual-porosity system, we start with a conceptual model for conservative tracer transport in fractured systems originally introduced by Maloszewski and Zuber $(1983,1985)$, and we extend it to include rate-limited, nonlinear sorbing tracer transport. Figure B-1 shows the assumed model domain, which consists of parallel-plate fractures of aperture $2 b$ separated by matrix blocks of thickness $L$, each of which extend infinitely into the page. Tang et al. (1981) assumed an infinite spacing between fractures, but this is just a special case of a finite matrix with a very large fracture spacing. Others have used similar model conceptualizations but with cylindrical or spherical-shaped matrix blocks (Rasmuson and Neretnieks, 1986). All of these formulations yield similar results when tracer penetration into the matrix is much less than matrix block dimensions; that is, when time scales are short compared to time scales necessary for diffusion to the centerline of the blocks. In Figure B-1, the fracture apertures, fracture flow velocity, matrix bulk density, matrix porosity, and fracture and matrix sorption parameters are assumed to be the same everywhere in the system (no spatial heterogeneity). This is clearly a simplification, but spatial variation is very difficult to characterize in a field setting, and it also introduces considerable complexity and ambiguity to model interpretations (i.e., more adjustable parameters to fit an observed response). Therefore, we considered it appropriate, as a first approximation, to assume homogeneous properties and use bulk average parameter values.

Referring to Figure B-1, it is assumed that advective transport occurs only in the $\mathrm{X}$ direction in the fractures and that diffusion into the matrix is important only in the y-direction. It is also assumed that there are no concentration gradients in the $y$-direction in the fractures. These assumptions allow the equations describing transport in the fractures and the matrix to be decoupled and solved as separate 1-dimensional problems that are linked only through a boundary condition and a single term in the fracture transport equation.

\section{Constant Flow Velocity in Fractures}

For a constant flow velocity in fractures (i.e., linear flow), the differential equations and boundary conditions describing rate-limited, nonlinear sorbing tracer transport in the fractures and matrix (the most general case) are

Fractures, Solution Phase:

$$
\frac{\partial C_{f}}{\partial t}+v_{f} \frac{\partial C_{f}}{\partial x}-D_{f} \frac{\partial^{2} C_{f}}{\partial x^{2}}+\left(\frac{\rho_{f}}{\eta}\right) \frac{\partial S_{f}}{\partial t}-\left.\frac{\phi D_{m}}{b \eta} \frac{\partial C_{m}}{\partial y}\right|_{y=b}=0
$$

Fractures, Immobile Phase:

$$
\left(\frac{\rho_{f}}{\eta}\right) \frac{\partial S_{f}}{\partial t}-k_{f f}\left(\frac{C_{f}^{\beta_{f}}}{1+\alpha_{f} C_{f}}\right)+k_{f r} S_{f}=0
$$


Matrix, Solution Phase:

$$
\frac{\partial C_{m}}{\partial t}-D_{m} \frac{\partial^{2} C_{m}}{\partial y^{2}}+\left(\frac{\rho_{B}}{\phi}\right) \frac{\partial S_{m}}{\partial t}=0
$$

Matrix, Immobile Phase:

$$
\left(\frac{\rho_{\mathrm{B}}}{\phi}\right) \frac{\partial \mathrm{S}_{\mathrm{m}}}{\partial \mathrm{t}}-\mathrm{k}_{\mathrm{mf}}\left(\frac{\mathrm{C}_{\mathrm{m}}^{\beta_{\mathrm{m}}}}{1+\alpha_{\mathrm{m}} \mathrm{C}_{\mathrm{m}}}\right)+\mathrm{k}_{\mathrm{mr}} \mathrm{S}_{\mathrm{m}}=0
$$

subject to initial and boundary conditions

$$
\begin{aligned}
& C_{f}(x, 0)=0 \\
& C_{f}(0, t)=\delta(t) \\
& C_{f}(\infty, t)=0 \\
& S_{f}(x, 0)=0 \\
& C_{m}(y, x, 0)=0 \\
& C_{m}(b, x, t)=C_{f}(x, t) \\
& \frac{\partial C_{m}}{\partial y}\left(\frac{L}{2}, x, t\right)=0 \\
& S_{m}(y, x, 0)=0
\end{aligned}
$$

where $\quad C_{f}=$ tracer concentration in solution in fractures, $M / L^{3}$

$\mathrm{C}_{\mathrm{m}}=$ tracer concentration in solution in matrix, $\mathrm{M} / \mathrm{L}^{3}$

$\mathrm{S}_{\mathrm{f}}=$ tracer surface concentration on fracture surfaces, $\mathrm{M} / \mathrm{M}$ solid

$\mathrm{S}_{\mathrm{m}}=$ tracer surface concentration on matrix surfaces, $M / M$ solid

$\mathrm{v}_{\mathrm{f}}=$ fluid velocity in fractures, $\mathrm{L} / \mathrm{T}$

$\mathrm{D}_{\mathrm{f}}=$ dispersion coefficient in fractures, $\mathrm{L}^{2} / \mathrm{T}$

$\mathrm{D}_{\mathrm{m}}=$ molecular diffusion coefficient in matrix, $\mathrm{L}^{2} / \mathrm{T}$

$\rho_{\mathrm{f}}=$ bulk density of material in fractures, $M / \mathrm{L}^{3}$

$\rho_{B}=$ bulk density of matrix, $M / L^{3}$

$\eta=$ porosity within fractures,

$\phi=$ matrix porosity,

$\mathrm{b}=$ fracture half aperture, $\mathrm{L}$

$\mathrm{L}=$ distance between parallel fractures in medium, $\mathrm{L}$

$\mathrm{k}_{\mathrm{ff}}=$ rate constant for sorption to surfaces in fractures, $1 / \mathrm{T}$ (if linear)

$\mathrm{k}_{\mathrm{fr}}=$ rate constant for desorption from surfaces in fractures, $\mathrm{M} / \mathrm{L}^{3} \mathrm{~T}$

$\mathrm{k}_{\mathrm{mf}}=$ rate constant for sorption to surfaces in matrix, $1 / \mathrm{T}$ (if linear)

$\mathrm{k}_{\mathrm{mr}}=$ rate constant for desorption from surfaces in matrix, $M / \mathrm{L}^{3} \mathrm{~T}$

$\alpha_{i}, \beta_{i}=$ sorption isotherm parameters defined in equation (B5) $(i=f$, fractures; $\mathrm{i}=\mathrm{m}$, matrix), and

$\delta(t)=$ dirac delta function.

Coupling between the fractures and matrix is achieved through boundary condition (B3b) and through the last term on the left-hand side of equation (B1). We make use of the expression 
$\left(\frac{\rho_{f}}{\eta}\right)$ to account for surface area available for sorption in fractures. In reality, fractures could be completely open (i.e., $\eta=1, \rho_{\mathrm{f}}=0$ ), and sorption might occur only on the walls. In this case, the expression $\left(\frac{\rho_{f}}{\eta}\right)$ can be considered a proportionality constant that should be adjusted to an appropriate value to describe sorption to the walls. Alternatively, sorption in fractures can be completely ignored by setting this term equal to zero. We use the dirac-delta function as the inlet boundary condition (equation (B1b)) because the solutions obtained using this boundary condition are residence time distributions that can be mathematically convoluted with any generalized input function to obtain a generalized breakthrough curve.

In the above equations, we have used a general expression for the sorption isotherms in both the fractures and the matrix:

$$
S=\frac{K C^{\beta}}{1+\alpha C}
$$

This expression allows a linear, a Freundlich, or a Langmuir isotherm to be defined. A Freundlich isotherm is obtained by setting $\alpha=0$, a Langmuir isotherm is obtained by setting $\beta=$ 1 , and a linear isotherm is obtained by setting $\alpha=0$ and $\beta=1$. Equations (B2) and (B4) also assume nonlinearity of the adsorption reaction (i.e., not first-order in concentration) while the desorption reaction is assumed to be linear (first-order in surface concentration). Note that $\mathrm{K}=$ $\mathrm{k}_{\mathrm{f}} / \mathrm{k}_{\mathrm{m}}$, where $\mathrm{k}_{\mathrm{f}}$ and $\mathrm{k}_{\mathrm{m}}$ are the rate constants for sorption and desorption, respectively. A nonsorbing tracer can be simulated by simply setting $\mathrm{K}$ equal to 0 .

If equilibrium sorption is assumed, the sorption isotherm expression can be substituted directly for $S_{f}$ and $S_{m}$ in equations (B1) and (B3), respectively. This eliminates the need for the immobile phase equations (B2) and (B4). Recognizing that $\frac{\partial S}{\partial t}=\frac{\partial S}{\partial C} \cdot \frac{\partial C}{\partial t}$, the fracture and matrix transport equations become

Fractures:

$$
\frac{\partial C_{f}}{\partial t}+v_{f} \frac{\partial C_{f}}{\partial x}-D_{f} \frac{\partial^{2} C_{f}}{\partial x^{2}}+\left(\frac{\rho_{f}}{\eta}\right)\left[\frac{K_{f} \beta_{f} C_{f}^{\beta_{f}-1}}{1+\alpha_{f} C_{f}}-\frac{\alpha_{f} K_{f} C_{f}^{\beta_{f}}}{\left(1+\alpha_{f} C_{f}\right)^{2}}\right] \frac{\partial C_{f}}{\partial t}-\left.\frac{\phi D_{m}}{b \eta} \frac{\partial C_{m}}{\partial y}\right|_{y=b}=0
$$

Matrix:

$$
\frac{\partial C_{m}}{\partial t}-D_{m} \frac{\partial^{2} C_{m}}{\partial y^{2}}+\left(\frac{\rho_{B}}{\phi}\right)\left[\frac{K_{m} \beta_{m} C_{m}^{\beta_{m}-1}}{1+\alpha_{m} C_{m}}-\frac{\alpha_{m} K_{m} C_{m}{ }^{\beta_{m}}}{\left(1+\alpha_{m} C_{m}\right)^{2}}\right] \frac{\partial C_{m}}{\partial t}=0
$$

where the terms in brackets, [], are $\frac{\partial S}{\partial C}$ for the fractures and matrix, respectively, and $K_{m}=\frac{k_{m f}}{k_{m r}}$ and $K_{f}=\frac{k_{f f}}{k_{f r}}$. 
When the sorption isotherm is nonlinear (either rate-limited or equilibrium), the appropriate equations given above must be solved numerically.

For linear sorption isotherms (either rate-limited or equilibrium), it is possible to obtain a semi-analytical solution of the transport equations by following the Laplace transform method of Maloszewski and Zuber (1983). The Laplace transform removes the time derivatives from the governing equations, rendering them ordinary differential equations that can be solved by standard methods. The Laplace transforms of the general rate-limited equations (B1), (B2), (B3), and (B4), assuming linear isotherms, are

Fractures, Solution Phase:

$$
s \overline{C_{f}}+v_{f} \frac{\partial \overline{C_{f}}}{\partial x}-D_{f} \frac{\partial^{2} \overline{C_{f}}}{\partial x^{2}}+\left(\frac{\rho_{f}}{\eta}\right) s \overline{S_{f}}-\left.\frac{\phi D_{m}}{b \eta} \frac{\partial \overline{C_{m}}}{\partial y}\right|_{y=b}=0
$$

Fractures, Immobile Phase:

$$
\left(\frac{\rho_{f}}{\eta}\right) s \overline{S_{f}}-k_{f f} \overline{C_{f}}+k_{f r} \bar{S}_{f}=0
$$

Matrix, Solution Phase:

$$
s \overline{C_{m}}-D_{m} \frac{\partial^{2} \overline{C_{m}}}{\partial y}+\left(\frac{\rho_{B}}{\phi}\right) s \overline{S_{m}}=0
$$

Matrix, Immobile Phase:

$$
\left(\frac{\rho_{B}}{\phi}\right) s \overline{S_{m}}-k_{m f} \overline{C_{m}}+k_{m r} \overline{S_{m}}=0
$$

where $\quad s=$ Laplace transform independent variable (replacing time), and

$\bar{X}=$ Laplace transform of dependent variable.

Equations (B9) and (B11) are now algebraic equations that can be solved for $\overline{\mathrm{S}}$, and the result(s) can be substituted into equations (B8) and (B10) to obtain (see also, Maloszewski and Zuber, 1991)

Fractures:

$$
\left[1+\frac{\left(\frac{\rho_{f}}{\eta}\right) k_{f f}}{\left(\frac{\rho_{f}}{\eta}\right) s+k_{f r}}\right] s \bar{C}_{f}+v_{f} \frac{\partial \bar{C}_{f}}{\partial x}-D_{f} \frac{\partial^{2} \bar{C}_{f}}{\partial x^{2}}-\left.\frac{\phi D_{m}}{b \eta} \frac{\partial \overline{C_{m}}}{\partial y}\right|_{y=b}=0
$$


Matrix:

$$
\left[1+\frac{\left(\frac{\rho_{\mathrm{B}}}{\phi}\right) \mathrm{k}_{\mathrm{mf}}}{\left(\frac{\rho_{\mathrm{B}}}{\phi}\right) \mathrm{s}+\mathrm{k}_{\mathrm{mr}}}\right] \overline{\mathrm{C}} \overline{\mathrm{m}}_{\mathrm{m}}-\mathrm{D}_{\mathrm{m}} \frac{\partial^{2} \overline{\mathrm{C}_{\mathrm{m}}}}{\partial \mathrm{y}^{2}}=0
$$

The equilibrium sorption case is readily apparent from equations (B12) and (B13) if we set $k_{f}$ and $k_{r}$ to very large values and recognize that $K_{d}=\frac{k_{f}}{k_{r}}$ and $R=1+\left(\frac{\rho_{B}}{\phi}\right) K_{d}$. The equilibrium case was also derived by Tang et al. (1981) for an infinite matrix boundary condition.

Equations (B12) and (B13) are in the same form as the equations solved by Maloszewski and Zuber (1983). The only difference is that the sorption expressions in brackets in equations (B12) and (B13) were equal to 1 in Maloszewski and Zuber's equations because they only considered conservative solute transport. Thus, the solution of equations (B12) and (B13) subject to Laplace-transformed boundary conditions (B1a) through (B4a) is identical to the solution presented by Maloszewski and Zuber except that the $s \overline{\mathrm{C}}_{\mathrm{f}}$ and $\mathrm{s} \overline{\mathrm{C}}_{\mathrm{m}}$ terms now have more complicated coefficients. Referring to Maloszewski and Zuber (1983) for details of the derivation, the final result for transport in the fractures coupled with diffusion into the matrix is a single Laplace-domain equation given by

$$
\bar{C}_{f}(x)=\exp \left\{\frac{v_{f} x}{2 D_{f}}\left[1-\sqrt{1+\frac{4 D_{f} R_{f}(s)}{v_{f}^{2}} s+\frac{4 D_{f} \phi}{v_{f}^{2} b \eta} \sqrt{R_{m}(s) D_{m} s} \operatorname{Tanh}\left(\sqrt{\frac{s R_{m}(s)}{D_{m}}\left(\frac{L}{2}-b\right)}\right)}\right]\right\}
$$

where

$$
\begin{aligned}
& R_{f}(s)=1+\frac{\left(\frac{\rho_{f}}{\eta}\right) k_{f f}}{\left(\frac{\rho_{f}}{\eta}\right) s+k_{f r}} \\
& R_{m}(s)=1+\frac{\left(\frac{\rho_{B}}{\phi}\right) k_{m f}}{\left(\frac{\rho_{B}}{\phi}\right) s+k_{m r}}
\end{aligned}
$$


If we introduce the mean fluid residence time in fractures, $\tau=\frac{x}{v_{f}}$, and the dimensionless Peclet number, $P e=\frac{X v_{f}}{D_{f}}$, which are related to the first and second moments of fluid residence time in the system, respectively, equation (B14) can be rewritten as

$$
\bar{C}_{f}(x)=\exp \left\{\frac{P e}{2}\left[1-\sqrt{1+\frac{4 \tau}{P e}\left\{s R_{f}(s)+\frac{\phi}{b \eta} \sqrt{R_{m}(s) D_{m} s} \operatorname{Tanh}\left(\sqrt{\frac{s R_{m}(s)}{D_{m}}\left(\frac{L}{2}-b\right)}\right)\right\}}\right]\right.
$$

Equation (B17) is arguably a more natural expression to work with than equation (B14) when considering field data because actual distances and fluid velocities in a field experiment will be dependent on flow pathways in the system, but the concepts of the first and second moments of fluid residence time are less ambiguous. Equation (B17) also clearly delineates the expression $\frac{\phi}{b \eta} \sqrt{R_{m}(s) D_{m}}$ as an effective mass transfer coefficient for matrix diffusion. This expression can be further divided into a flow-system-dependent part, $\frac{\phi}{\mathrm{b} \eta}$, and a tracer-dependent part, $\sqrt{R_{m}(s) D_{m}}$. In chemical engineering, Laplace-domain expressions such as equations (B14) and (B17) are used extensively in control theory and are referred to as "transfer functions."

We now consider three simplifications to equation (B17). First, by setting $R_{f}(s)$ and $\mathrm{R}_{\mathrm{m}}(\mathrm{s})$ equal to 1 , we reproduce the result for a nonsorbing tracer obtained by Maloszewski and Zuber (1983). Second, in the case of an infinite matrix, as was assumed by Tang et al. (1981), the argument of the hyperbolic tangent approaches infinity and hence the hyperbolic tangent itself becomes unity. The resulting expression is identical to that derived by Tang et al. (1981) except that the reaction terms have now been generalized to allow rate-limited as well as equilibrium sorption. Finally, if we set the matrix porosity, $\phi$, equal to zero, the entire term accounting for diffusive transport in the matrix (the term containing the hyperbolic tangent) drops out of the equation, and we get an expression describing reactive transport in a singleporosity medium. Thus, the transport expression derived for a dual-porosity medium also applies to a single-porosity medium when $\phi=0$.

\section{Radial Convergent Flow in Fractures}

The derivations in the preceding section were strictly for a constant flow rate in fractures (linear flow). In reality, the flow field in a weak recirculation tracer test in a confined, heterogeneous aquifer is likely to range between linear and radial (National Research Council, 1996), with these two cases representing end members. In a completely unconfined aquifer, spherical flow might be an appropriate end member, but we do not consider that here.

In the case of radial flow, we only have to modify the equations for solution phase transport in the fractures in the preceding section. Specifically, all $\mathrm{x}$-derivatives become $\mathrm{r}$ - 
derivatives and the $D_{f} \frac{\partial^{2} C_{f}}{\partial x^{2}}$ terms become $\left(\frac{1}{r}\right) \frac{\partial}{\partial r}\left(\mathrm{rD}_{\mathrm{f}} \frac{\partial \overline{\mathrm{C}_{\mathrm{f}}}}{\partial \mathrm{r}}\right)$. Equations (B1), (B6), (B8), and (B12) then become, respectively,

$$
\begin{gathered}
\frac{\partial C_{f}}{\partial t}+v_{f} \frac{\partial C_{f}}{\partial r}-\left(\frac{1}{r}\right) \frac{\partial}{\partial r}\left(r D_{f} \frac{\partial C_{f}}{\partial r}\right)+\left(\frac{\rho_{f}}{\eta}\right) \frac{\partial S_{f}}{\partial t}-\left.\frac{\phi D_{m}}{b \eta} \frac{\partial C_{m}}{\partial y}\right|_{y=b}=0 \\
\frac{\partial C_{f}}{\partial t}+v_{f} \frac{\partial C_{f}}{\partial r}-\left(\frac{1}{r}\right) \frac{\partial}{\partial r}\left(r D_{f} \frac{\partial C_{f}}{\partial r}\right)+\left(\frac{\rho_{f}}{\eta}\right)\left[\frac{K_{f} \beta_{f} C_{f}^{\beta_{f}-1}}{1+\alpha_{f} C_{f}}-\frac{\alpha_{f} K_{f} C_{f}^{\beta_{f}}}{\left(1+\alpha_{f} C_{f}\right)^{2}}\right] \frac{\partial C_{f}}{\partial t}-\left.\frac{\phi D_{m}}{b \eta} \frac{\partial C_{m}}{\partial y}\right|_{y=b}=0 \\
s \overline{C_{f}}+v_{f} \frac{\partial \overline{C_{f}}}{\partial r}-\left(\frac{1}{r}\right) \frac{\partial}{\partial r}\left(r D_{f} \frac{\partial \overline{C_{f}}}{\partial r}\right)+\left(\frac{\rho_{f}}{\eta}\right) s \bar{S}_{f}-\left.\frac{\phi D_{m}}{b \eta} \frac{\partial \bar{C}_{m}}{\partial y}\right|_{y=b}=0 \\
{\left[1+\frac{\left(\frac{\rho_{f}}{\eta}\right) k_{f f}}{\left(\frac{\rho_{f}}{\eta}\right) s+k_{f r}}\right] s \bar{C}_{f}+v_{f} \frac{\partial \bar{C}_{f}}{\partial r}-\left(\frac{1}{r}\right) \frac{\partial}{\partial r}\left(r D_{f} \frac{\partial \overline{C_{f}}}{\partial r}\right)-\left.\frac{\phi D_{m}}{b \eta} \frac{\partial \bar{C}_{m}}{\partial y}\right|_{y=b}=0}
\end{gathered}
$$

All other equations are the same as for the linear flow case if the model domain is the same as in Fig. B-1.

Becker (1996) has solved the radial flow transport problem in the special case of convergent flow with no sorption or matrix diffusion (i.e., a single-porosity system). His solution differs from other radial convergent transport solutions in the literature (e.g., Moench, $1989,1995)$ in that his boundary condition at the production well is an "absorbing" boundary; i.e., any solute mass reaching the production well immediately disappears from the system. This boundary condition is consistent with a transfer function approach to interpreting tracer test responses, discussed below. The resulting Laplace domain solution for the case of no sorption or matrix diffusion in terms of $\tau$ and $\mathrm{Pe}$ (analogous to equation (B17)) is (Becker, 1996)

$$
\bar{C}_{f}\left(r_{W}\right)=\exp \left[\frac{\operatorname{Pe}}{2}\left(1-\frac{1}{r_{L W}}\right)\right] \frac{\operatorname{Ai}\left(\sigma^{1 / 3} y_{L}\right)}{\operatorname{Ai}\left(\sigma^{1 / 3} y_{W}\right)}
$$

where $r_{w}=$ production well radius,

$\mathbf{r}_{\mathrm{LW}}=$ production well radius divided by separation between injection and production wells,

$$
\begin{aligned}
& y_{L}=P e+\frac{1}{4 \sigma}, \\
& y_{W}=\frac{P e}{r_{L W}}+\frac{1}{4 \sigma},
\end{aligned}
$$




$$
\begin{aligned}
& \sigma=\left(\frac{\mathrm{r}_{\mathrm{LW}}}{\mathrm{Pe}}\right)^{2} \frac{2 \tau \mathrm{s}}{\left(\mathrm{r}_{\mathrm{LW}}{ }^{2}-1\right.} \text {, and } \\
& \operatorname{Ai}(\mathrm{z}) \text { = Airy function (Spanier and Oldham, 1987). }
\end{aligned}
$$

Becker (1996) extended this result to a dual-porosity system (with the geometry of Figure B-1) for a tracer that exhibits equilibrium, linear sorption behavior. We extend it further here to allow for rate-limited, linear sorption. The result, without derivation, is identical to equation (B22) but with $\sigma$ redefined as

$$
\sigma=\left(\frac{\mathrm{r}_{\mathrm{LW}}}{\mathrm{Pe}}\right)^{2} \frac{2 \tau \mathrm{s} \Psi(\mathrm{s})}{\left(\mathrm{r}_{\mathrm{LW}}{ }^{2}-1\right.}
$$

where $\Psi(s)=R_{f}(s)+\frac{\phi}{b \eta} \sqrt{\frac{R_{m}(s) D_{m}}{s}} \operatorname{Tanh}\left(\sqrt{\frac{s R_{m}(s)}{D_{m}}}\left(\frac{L}{2}-b\right)\right)$ and $R_{f}(s)$ and $R_{m}(s)$ are as defined in equations (B15) and (B16).

Equation (B22) using $\sigma$ defined in equation (B23) is the Laplace transform transfer function expression that should be used instead of equation (B17) for the case of radial convergent transport of a linearly sorbing tracer in a dual-porosity system. For nonlinear sorption, a numerical formulation of equation (B18) in conjunction with equations (B2), (B3), and (B4) is required for the rate-limited case, and equations (B19) and (B7) are required for the equilibrium case.

\section{Convolution of Transfer Functions to Obtain Tracer Test Responses}

Before we can obtain a meaningful field-scale transport prediction, we must convolute equation (B17) or (B22) with a realistic tracer injection function. In the time domain, such a convolution is accomplished by a convolution integral, but in the Laplace domain it becomes a simple multiplication (Churchill, 1958):

$$
\mathrm{C}(\mathrm{t})=\int_{0}^{\mathrm{t}} \mathrm{A}(\tau) \cdot \mathrm{B}(\mathrm{t}-\tau) \mathrm{d} \tau \Rightarrow \overline{\mathrm{C}}(\mathrm{s})=\overline{\mathrm{A}}(\mathrm{s}) \cdot \overline{\mathrm{B}}(\mathrm{s})
$$

where, $\quad X(t)=$ time-domain function,

$\bar{X}(s)=$ Laplace transform of time-domain function, and

$\mathrm{s}=$ Laplace transform variable.

This process can be extended to more than two transfer functions by taking the product of all applicable functions. Thus, in a field tracer test, transfer functions for tracer injection, pipeline delays, and storage in the injection and production wellbores can all easily be convoluted with the groundwater system transfer function (e.g., equations (B17) or (B22)) to obtain an overall transfer function for the test. We assume the most practical injection function 
in a field tracer test: a finite-duration, constant concentration pulse, which has a Laplace transform given by

$$
\bar{I}(s)=C_{o}\left(\frac{1-\exp \left(-T_{p} s\right)}{s}\right)
$$

where $\quad C_{0}=$ concentration of injection pulse, $M / L^{3}$, $T_{p}=$ duration of injection pulse, $T$.

Wellbore storage is accounted for by assuming that the wellbores are well-mixed regions (Moench, 1989, 1995). The Laplace domain transfer function for a well-mixed region is given by

$$
\bar{W}(s)=\frac{\gamma}{\gamma+s}
$$

where $\gamma=$ time constant, generally assumed to be the volumetric flow rate divided by the volume of well-mixed region, $1 / \mathrm{T}$.

Pipeline delays can be accounted for by a transfer function of the form

$$
\overline{\mathrm{P}}(\mathrm{s})=\exp \left(-\mathrm{T}_{\mathrm{d}} \mathrm{s}\right)
$$

where $T_{d}=$ delay time, $T$.

Reinjection of tracers can also be accounted for with transfer functions, but that is not considered here because there was no recirculation in the BULLION forced-gradient experiment.

A computer model called RELAP (REactive transport LAPlace transform inversion code) was developed to predict field tracer transport by convoluting (i.e., multiplying) either the linear or radial dual-porosity transfer functions (equations (B17) or (B22), respectively) with the transfer functions described above. RELAP numerically inverts the resulting Laplace-domain product of transfer functions to obtain a time domain solution. The numerical inversion procedure is described in the next section.

The Laplace transform approach has a distinct advantage over numerical modeling in that it is very easy to account for the effects of processes other than transport in the aquifer (by the convolution procedure described above). The transfer function approach is also well suited to estimating model parameters by matching solutions to experimental breakthrough curves. The Laplace transform inversion executes in a fraction of a second on a typical computer workstation, so RELAP can be exercised with different values of transport parameters literally thousands of times per minute. By contrast, a typical numerical simulation with comparable numerical accuracy can take several minutes of compute time on the same workstation. RELAP contains a parameter search algorithm to minimize the sum-of-squares differences between model predictions and tracer test data. Up to four data sets can be simultaneously fitted to obtain 
transport parameters. This feature allows rapid estimation of model parameter values that are consistent with all data sets, not just a single breakthrough curve.

RELAP was tested by (1) inverting several simple Laplace transforms with known timedomain solutions to ensure that the Laplace transform inversion algorithm was working properly, and (2) comparing predicted nonsorbing solute breakthrough curves in a single-porosity medium to analytical solutions (Kreft and Zuber, 1978; Levenspiel, 1972). In all cases, excellent agreement was obtained between the model predictions and the analytical solutions.

\section{Numerical Inversion of Laplace Transforms}

The final step in obtaining a transport prediction from the transfer functions is to invert the solution from the Laplace domain to the time domain. We accomplish this by using a Fourier transform procedure embodied in an algorithm obtained over the World Wide Web (Lindhardt, 1995). We have found this algorithm to be more stable for Laplace transform inversions than any others we have tried (e.g., Stehfest, 1970; de Hoog et al., 1982).

The basic principles of the algorithm used for numerical inversion of Laplace transforms are given below. We thank Sven Lindhardt (unknown affiliation) for providing the algorithm (Lindhardt, 1995) in the form of a MathCad ${ }^{\circledR}$ worksheet at the World Wide Web address: http://www.mathsoft.com/appsindex.html. The worksheet can be found under the program name invrsfft.mcd at this web site. Sven also provided much of the following description of the mathematical basis for the algorithm.

The Laplace transform is defined by

$$
F(s)=\int_{0}^{\infty} f(t) e^{-s t} d t
$$

where $\mathbf{s}=$ Laplace transform variable,

$\mathrm{t}=$ time,

$f(t)=$ time domain function, and

$F(s)=$ Laplace domain function.

If we set $\mathrm{s}=\sigma+\mathrm{j} \omega$, where $\mathrm{j}=\sqrt{-1}$, in equation (B28) and change the lower limit of integration to $-\infty$ (which is permissible for any initial-valued problem because $f(t)=0$ for $t<0$ ) we obtain

$$
F(s)=\int_{-\infty}^{\infty} f(t) e^{-\sigma t} e^{-j \omega t} d t
$$

If $\sigma$ is a constant, equation (B29) can be rewritten as

$$
F(j \omega)=\int_{-\infty}^{\infty} f_{1}(t) e^{-j \omega t} d t
$$


where $f_{1}(t)=f(t) e^{-o t}$.

Equation (B30) is the Fourier transform of $f_{1}(t)$, for which very efficient inversion algorithms exist to find $f_{1}(t)$ given $F(j \omega)$. However, the choice of $\sigma$ must be such that the integral in equation (B30) converges. This is accomplished by choosing

$$
\sigma=\frac{-\ln (0.05)}{1.5 \cdot T_{\max }}
$$

where $\quad T_{\max }=$ maximum time at which the function $f(t)$ is to be evaluated.

Now, if we have an arbitrary Laplace transform, $\mathrm{F}(\mathrm{s})$, we can obtain a spectrum by setting $\mathrm{s}=$ $\sigma+\mathrm{j} \omega$ and computing $\mathrm{F}(\mathrm{s})$ for equally-spaced values of $\omega$; i.e., for

$$
\omega_{\mathrm{i}}=\frac{2 \pi \mathrm{i}}{\mathrm{T}_{\max }}
$$

where $\quad \mathrm{i}=0,1,2,3 \ldots$

The inverse Fourier transform of this spectrum will give the function $f_{1}(t)$ in equation (B30), from which the desired function $f(t)$ is easily generated from

$$
f(t)=f_{1}(t) e^{\sigma t} .
$$

The inversion algorithm has been extensively tested on equations where time-domain solutions are known, and it has proven to be very accurate. Accuracy for the purposes of this work was ensured by using more and more terms in the Fourier transforms until the solutions no longer changed.

\section{Appendix B References}

Becker, M. W., Tracer tests in a fractured rock and their first passage time mathematical models, Ph.D. dissertation, University of Texas at Austin, 1996.

Churchill, R. V., Operational Mathematics, 2nd ed., McGraw-Hill, New York, 1958.

de Hoog, F. R., Knight, J. H., and Stokes, A. N., An improved method for numerical inversion of Laplace transforms, SLAM Journal on Scientific and Statistical Computing, 3(3), 357-366, 1982. 
Kreft, A. and Zuber, A., On the physical meaning of the dispersion equation and its solutions for different initial and boundary conditions, Chemical Engineering Science, 33, 1,471-1,480, 1978.

Levenspiel, O., Chemical Reaction Engineering, 2nd ed., John Wiley and Sons, New York, 1972.

Lindhardt, S., computer code invrsfft.med (1995), as MathCad ${ }^{\circledR}$ worksheet available at http://www.mathsoft.com/appsindex.html, 1999.

Maloszewski, P. and Zuber, A., Interpretation of artificial and environmental tracers in fissured rocks with a porous matrix, in Isotope Hydrology, International Atomic Energy Agency (IAEA), Vienna, Austria, pp. 635-651, 1983.

Maloszewski, P. and Zuber, A., On the theory of tracer experiments in fissured rocks with a porous matrix, Journal of Hydrology, 79, 333-358, 1985.

Maloszewski, P. and Zuber, A., Influence of matrix diffusion and exchange reactions on radiocarbon ages in fissured carbonate aquifers, Water Resources Research, 27(8), 1,937$1,945,1991$.

Moench, A. F., Convergent radial dispersion: A Laplace transform solution for aquifer tracer testing, Water Resources Research, 25(3), 439-447, 1989.

Moench, A. F., Convergent radial dispersion in a double-porosity aquifer with fracture skin: Analytical solution and application to a field experiment in fractured chalk, Water Resources Research, 31(8), 1823-1835, 1995.

National Research Council, Rock Fractures and Fluid Flow: Contemporary Understanding and Applications, National Academy Press, Washington, D.C., 1996.

Rasmuson, A. and Neretnieks, I., Radionuclide migration in strongly fissured zones: The sensitivity to some assumptions and parameters, Water Resources Research, 22(4), 559-569, 1986.

Spanier, J. and Oldham, K. B., An Atlas of Functions, Hemisphere Publishing, New York, 1987.

Stehfest, H., Numerical inversion of Laplace transforms, Communications of the ACM, 13, 47$49,1970$.

Tang, D. H., Frind, E. O., and Sudicky, E. A., Contaminant transport in a fractured porous media: Analytical solution for a single fracture, Water Resources Research, 17(3), 555-564, 1981. 

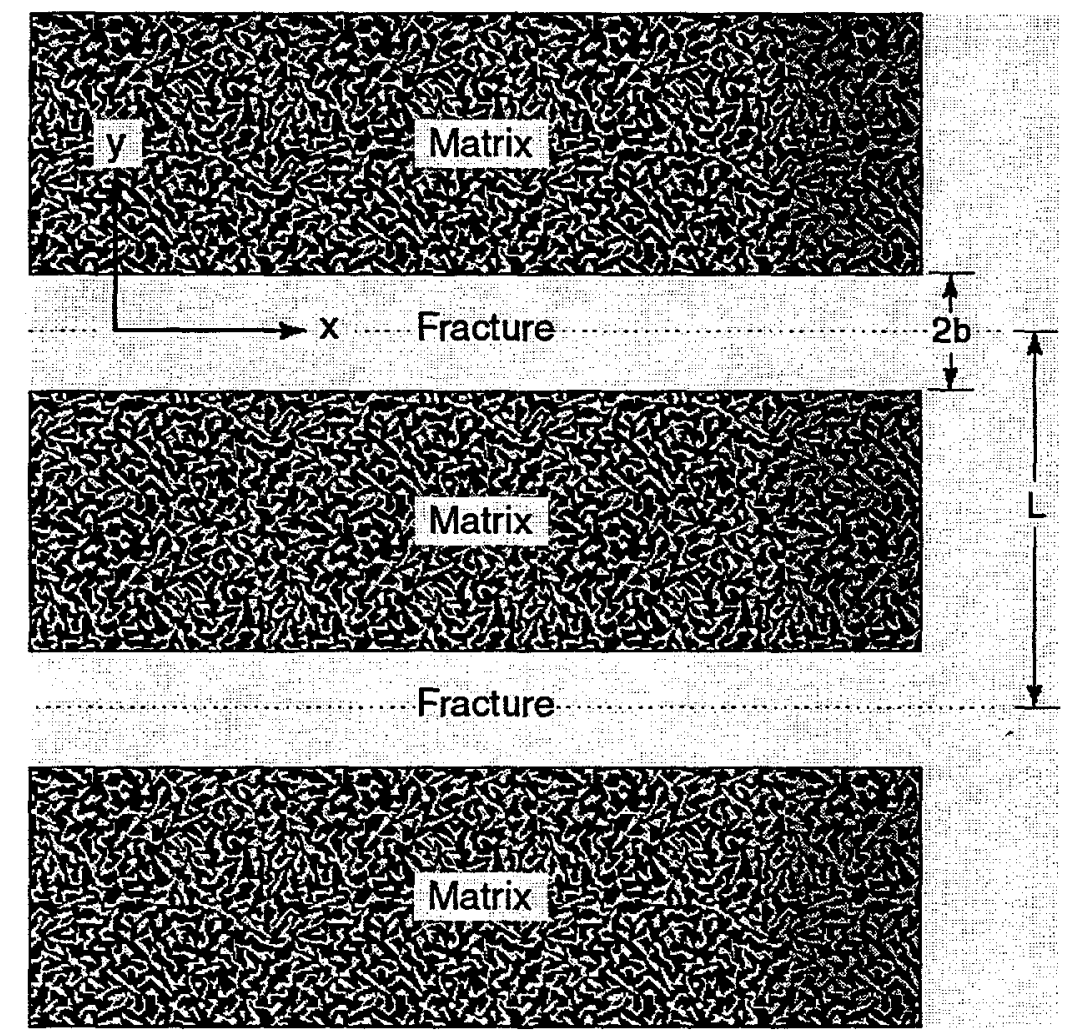

Figure B-1. System geometry assumed in conceptual dual-porosity model. 


\section{Distribution:}

Bob Bangerter

Department of Energy

P.O. Box 98518

Las Vegas, NV 89193

Cary Bronson

Department of Energy

P.O. Box 98518

Las Vegas, NV 89193

James Craig

Los Alamos National Laboratory

P.O. Box 98518

Las Vegas, NV 89193

Robert Curiale

International Technology Corp.

P.O. Box 93838

Las Vegas, NV 89193

Barb Deshler

International Technology Corp.

P.O. Box 93838

Las Vegas, NV 89193

Sig Drellack

Bechtel Nevada

P.O. Box 98521 MS/NLV 82

Las Vegas, NV 89193

William Fryer

International Technology Corp.

P.O. Box 93838

Las Vegas, NV 89193

Bruce Hurley

Department of Energy

P.O. Box 98518

Las Vegas, NV 89193

Roger Jacobson

Desert Research Institute

2215 Raggio Parkway

Reno, NV 89512
Annie Kersting

Lawrence Livermore National Laboratory

P.O. Box 808 L-231

Livermore, CA 94551

Randy Laczniak

USGS Water Resources Division

6770 Paradise Road

Las Vegas NV 89119

Ken Ortego

Bechtel Nevada

P.O. Box $98521 \mathrm{MS} / \mathrm{NLV}$

Las Vegas, NV 89193

Gayle Pawloski

Lawrence Livermore National Laboratory

P.O. Box 808 L-221

Livermore, CA 94551

Greg Pohll

Desert Research Institute

2215 Raggio Parkway

Reno, NV 89512

Ken Rehfeldt

HSI GeoTrans

P.O. Box 93838

Las Vegas, NV 89193

Chuck Russell

Desert Research Institute

755 E. Flamingo

Las Vegas, NV 89119

Donald Schaefer

USGS Water Resources Division

333 West Nye Lane

Carson City, NV 89706

Dave Smith

Lawrence Livermore National Laboratory

P.O. Box 808 L-231

Livermore, CA 94551 
Doug Trudeau

USGS Water Resources Division

6770 Paradise Road

Las Vegas, NV 89119

Rick Waddell

HSI GeoTrans

9101 Harlan St., Suite 210

Westminster, CO 80030

Janet Wille

International Technology Corp.

P.O. Box 93838

Las Vegas, NV 89193

Les Winfield

Department of Energy

P.O. Box 98518

Las Vegas, NV 89193

U.S. Department of Energy

Nevada Operations Office

Technical Information Resource Center

P.O. Box 98518

Las Vegas, NV 89193-8518
U.S. Department of Energy

Nevada Operations Office

Public Reading Facility

P.O. Box 98521

Las Vegas, NV 89193-8521

U.S. Department of Energy

Office of Scientific and Technical

Information

P.O. Box 62

Oak Ridge, TN 37831-0062

Los Alamos National Laboratory

P.O. Box 1663

Los Alamos, NM 87545

Dave Finnegan, MS-J514

Marc Haga, MS-J534 (3 copies)

Wayne Hansen, MS-K491

Ward Hawkins, MS-D462

Maureen McGraw, MS-F649

Paul Reimus, MS-J534

Joe Thompson, MS-J514

Rick Warren, MS-D462

Andy Wolfsberg, MS-F649 